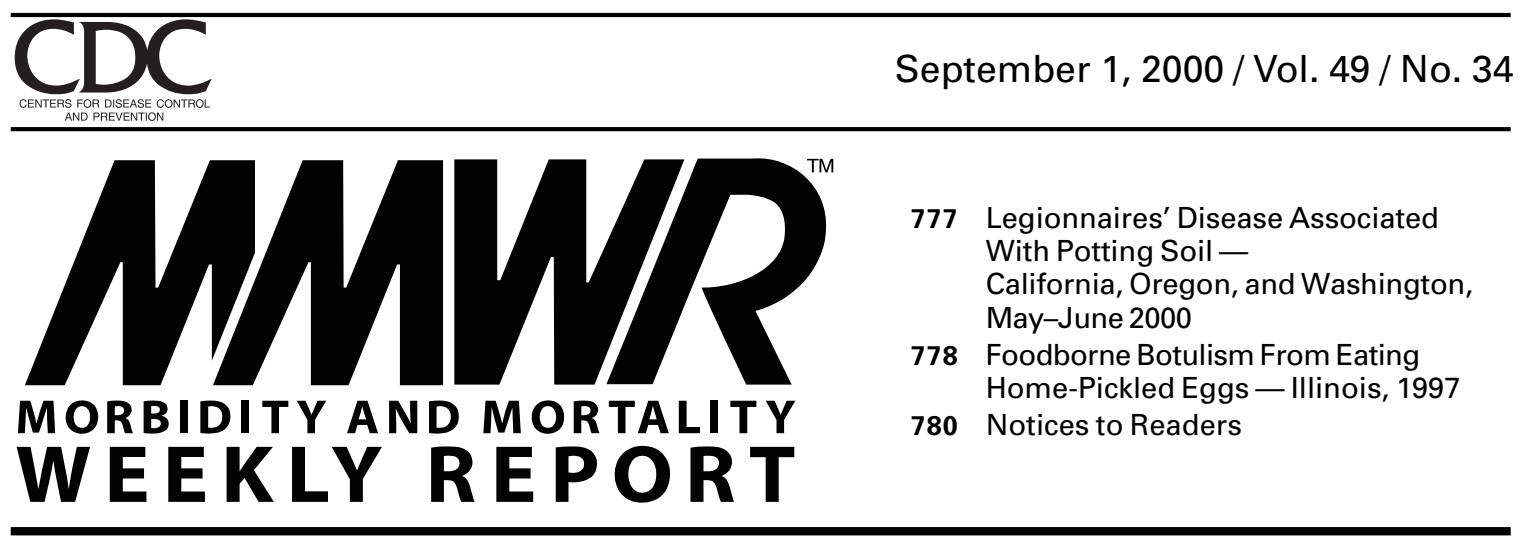

\title{
Legionnaires' Disease Associated With Potting Soil - California, Oregon, and Washington, May-June 2000
}

Since Legionnaires' Disease (LD) was first reported in 1976, outbreaks have been associated with airborne transmission of Legionella bacteria through cooling towers, showers, and other aerosolizing devices (1). However, most LD cases are sporadic, and the source and mode of infection in many cases are unknown. Infections with one species, Legionella longbeachae, have been associated with gardening and use of potting soil in Australia and Japan $(2,3)$. This report summarizes the findings of LD investigations in California, Oregon, and Washington, that suggest that transmission from potting soil has occurred for the first time in the United States, and that active surveillance and case finding are warranted to explore this association.

On June 13, 2000, CDC was alerted by a county health official in Washington of L. longbeachae infection in a 46-year-old woman who had been hospitalized with pneumonia. The patient reported that she had been potting plants during the 10 days before her symptoms began in May. An isolate from the patient's sputum was sent to CDC for species confirmation, and two samples of potting soil and one of compost from the original packages obtained from the patient's residence were sent for analysis. L. longbeachae was isolated from one potting soil sample. The compost contained other Legionella species but not longbeachae.

In May, two $L$. longbeachae isolates had been received at CDC from bronchial wash samples taken from both a 77-year-old Oregon woman and a 45-year-old California man who were both diagnosed with legionellosis. The California patient died and his house was cleaned before an investigation could be undertaken. State and local health officials determined that the Oregon patient had been potting plants using commercial potting soil mixtures and had been working in a home garden during the 10 days before her symptoms began in April. Two potting soil samples taken from her residence were tested for Legionella at CDC; one was positive for L. longbeachae. Isolates of $L$. longbeachae from the patients and soils will be compared using amplified fragment length polymorphism typing.

Reported by: JS Duchin, MD, J Koehler, DVM, Public Health-Seattle \& King County, Seattle; JM Kobayashi, MD, State Epidemiologist, Washington State Dept of Health; RM Rakita, MD, $K$ Olson, MD, NB Hampson, MD, Virginia Mason Medical Center, Seattle. DN Gilbert, MD, JM Jackson, Providence Portland Medical Center, Portland; KR Stefonek, MPH, MA Kohn, MD, State Epidemiologist, Oregon Dept of Human Svcs, Health Div. J Rosenberg, MD, D Vugia, MD, Acting State Epidemiologist, California Dept of Health Svcs. M Marchione-Mastroianni, CDC Foundation, Atlanta, Georgia. Respiratory Diseases Br, Div of Bacterial and Mycotic Diseases, National Center for Infectious Diseases; and EIS officers, CDC.

\section{U.S. DEPARTMENT OF HEALTH \& HUMAN SERVICES}


Legionnaires' Disease - Continued

Editorial Note: The findings in this report illustrate the importance of reporting cases of LD to local and state health officials and of culturing patient specimens for Legionella. Although urine antigen tests provide rapid and accurate diagnosis of Legionella pneumophila serogroup 1, these tests are not sensitive for other serogroups or species. Microbiologic and epidemiologic investigations are needed to identify less common species and may reveal risk factors and novel modes of disease transmission.

L. pneumophila serogroup 1 accounts for most legionellosis cases in the United States; L. longbeachae is reported less frequently. During 1990-1999, 37 cases of L. longbeachae were reported to CDC's Legionella reporting system. It is likely that legionellosis is underreported to CDC because of failure to obtain the appropriate diagnostic tests in cases of pneumonia of unknown etiology, difficulty of culturing Legionella from clinical specimens, and because legionellosis is not reportable in all states.

Soil surveys for Legionella have not been conducted in the United States; however, in a soil survey in Australia, $33(73 \%)$ of 45 potting soil samples tested positive for Legionella; 26 (79\%) of the 33 contained longbeachae (4). Nineteen (100\%) soil samples in Europe and the United Kingdom were negative for L. longbeachae. A survey of 17 soil samples in Japan in 1998 yielded 31 different strains of Legionella; eight of the 17 samples (47\%) contained L. longbeachae (3).

Health-care providers should report legionellosis cases to local or state health departments, and state health departments should report legionellosis cases, particularly L. longbeachae to CDC. Risk factors and behaviors associated with transmission of L. longbeachae are unknown; therefore, to better define the extent of disease, modes of transmission, and to develop prevention strategies, CDC urges state health departments to send Legionella cultures yielding non-pneumophila isolates to CDC's Legionella laboratory for speciation, telephone (404) 639-3563. Cases of L. longbeachae infection that have occurred during the previous 12 months should be reported to CDC's National Center for Infectious Diseases, Division of Bacterial and Mycotic Diseases, Respiratory Diseases Branch, telephone (404) 639-2215. For local and state use, a case report form may be obtained from the World-Wide Web, http://www.cdc.gov/ncidod/dbmd/diseaseinfo, and faxed to (404) 639-3970.

\section{References}

1. Fiore $A E$, Nuorti JP, Levine OS, et al. Epidemic Legionnaires' disease two decades later: old sources, new diagnostic methods. Clin Infect Dis 1998;26:426-33.

2. Steele TW, Lanser J, Sangster N. Isolation of Legionella longbeachae serogroup 1 from potting mixes. Appl Environ Microbiol 1990;56:49-53.

3. Koide M, Saito A, Okazaki M, et al. Isolation of Legionella longbeachae serogroup 1 from potting soils in Japan. Clin Infect Dis 1999;29:943-4.

4. Steele TW, Moore CV, Sangster N. Distribution of Legionella longbeachae serogroup 1 and other Legionella in potting soils in Australia. Appl Environ Microbiol 1990;56:2984-8.

\section{Foodborne Botulism From Eating Home-Pickled Eggs — Illinois, 1997}

During November 1997, the Illinois Department of Public Health was notified by a local physician about a possible case of foodborne botulism. This report summarizes the case investigation, which implicated home-pickled eggs as the cause.

On November 23, 1997, a previously healthy 68-year-old man became nauseated, vomited, and complained of abdominal pain. During the next 2 days, he developed diplopia, 
Foodborne Botulism - Continued

dysarthria, and respiratory impairment, necessitating hospitalization and mechanical ventilation. Physical examination confirmed multiple cranial nerve abnormalities, including extraocular motor palsy and diffuse flaccid paralysis. Possible botulism was diagnosed, and a one-vial dose of trivalent (types A, B, and E) antibotulinum toxin was administered. A sample of the patient's serum collected before antitoxin administration demonstrated the presence of type B botulinum toxin. A food history revealed no exposures to home-canned products; however, the patient had eaten pickled eggs that he had prepared 7 days before onset of illness; gastrointestinal symptoms began 12 hours after ingestion. The patient recovered after prolonged supportive care.

The pickled eggs were prepared using a recipe that consisted of hard-boiled eggs, commercially prepared beets and hot peppers, and vinegar. The intact hard-boiled eggs were peeled and punctured with toothpicks then combined with the other ingredients in a glass jar that closed with a metal screw-on lid. The mixture was stored at room temperature and occasionally was exposed to sunlight.

Cultures revealed Clostridium botulinum type B, and type B toxin was detected in samples of the pickled egg mixture at CDC's National Botulism Surveillance and Reference Laboratory. C. botulinum was cultured from the pickling liquid, beets, and egg yolk. The concentration of preformed type B toxin was 1000 times greater in the egg yolks than in the pickling liquid and was undetected in the beets. Peppers from the original commercial container contained no detectable toxin, and bacterial cultures of the peppers did not yield $C$. botulinum. Beets from the original commercial containers were not available. The $\mathrm{pH}$ of the pickling liquid was 3.5 (i.e., adequate to prevent $C$. botulinum germination and toxin formation. However, the $\mathrm{pH}$ of the egg yolk was not determined [normal egg yolk $\mathrm{pH}: 6.8]$ ).

Reported by: G Rifkin, MD, Rockford Memorial Hospital, Rockford; K Sibounheuang, L Peterson, Winnebago County Health Dept, Rockford; K Kelly, C Langkop, D Kauerauf, E Groeschel, B Adam, C Austin, DVM, S Bornstein, MD, Illinois Dept of Public Health. National Botulism Surveillance and Reference Laboratory, Foodborne and Diarrheal Diseases Br, Div of Bacterial and Mycotic Diseases, National Center for Infectious Diseases; and an EIS Officer, CDC.

Editorial Note: Botulism is a paralytic illness caused by the neurotoxin produced by the bacterium $C$. botulinum. Paralysis first affects the cranial nerves, then the skeletal muscles; untreated intoxications can lead to dense flaccid paralysis, respiratory failure, and death $(1,2)$.

Although rare and sporadic, foodborne botulism is a persistent cause of morbidity and mortality in the United States. In 1997, an annual survey of state epidemiologists and directors of state public health laboratories identified 24 cases of foodborne botulism with one associated death (CDC, unpublished data, 1998). During 1989-1998, a median of 23 cases (range: 17-42 cases) of foodborne botulism was reported each year with a median of one death (range: $0-2$ deaths).

C. botulinum spores are ubiquitous. Safe food preservation methods destroy spores or inhibit their germination and growth. Conditions that promote germination and growth of $C$. botulinum spores include absence of oxygen (anaerobic conditions), low acidity (pH $>4.6$ ), temperatures $>39 \mathrm{~F}$ [4 C]), and high moisture content. Most foodborne botulism cases that occur in the United States are the result of improperly home-canned foods. This is the first reported case of botulism related to eating pickled eggs. The amount of toxin detected in the recovered egg yolk suggested that bacterial growth was concentrated in that portion of the egg. Intact eggs that have been hard-boiled should be free of bacteria or spores. Pricking cooked eggs may introduce $C$. botulinum spores into the 
Foodborne Botulism - Continued

yolk. Portions of the yolk that remained anaerobic and inadequately pickled (i.e., not acidified to $\mathrm{pH} \leq 4.6$ ) may have allowed $C$. botulinum spores to germinate, grow, and form toxin. Setting the pickling jar in sunlight provided warmth that facilitated bacterial growth and toxin production.

To reduce the risk for botulism when pickling, food items should be washed and cooked adequately, and utensils, containers, and other surfaces in contact with food, including cutting boards and hands, should be cleaned thoroughly with soap and warm water. Containers (e.g., jars and lids) in which pickling will occur should be sterilized (e.g., placed in boiling water for the prescribed period published in the container instructions) (3). Adequate acidification to a $\mathrm{pH} \leq 4.6$ is essential. Refrigeration at $39 \mathrm{~F}(4 \mathrm{C})$ during pickling is advisable, especially in foods that may be acidified inadequately such as whole eggs. Once opened, any canned or pickled food should be refrigerated. Pricking, poking holes, or otherwise handling whole eggs in a manner that might allow spores or bacteria into the yolk should be avoided.

When foodborne botulism is suspected, clinicians and public health investigators should inquire about the preparation and eating of foods preserved by any home method (e.g., canning, pickling, curing, and fermenting). Persons seeking advice on home-food preservation should consult their local county or university cooperative extension service, or contact the U.S. Department of Agriculture Food Safety Hotline, telephone (800) 535-4555. CDC provides epidemiologic consultation and laboratory diagnostic services for suspected botulism cases and authorizes release of botulism antitoxin. Through state health departments, these services are available 24 hours a day from CDC.

\section{References}

1. Shapiro RL, Hatheway C, Swerdlow DL. Botulism in the United States: a clinical and epidemiologic review. Ann Intern Med 1998;129:221-8.

2. CDC. Botulism in the United States, 1899-1996: handbook for epidemiologists, clinicians, and laboratory workers. Atlanta, Georgia: US Department of Health and Human Services, CDC, 1998. Available at http://www.cdc.gov/ncidod/dbmd/diseaseinfo. Accessed August 2000.

3. Extension Service. Complete guide to home canning. Washington, DC: US Department of Agriculture, Extension Service, September 1994 (bulletin no. 539). Available at http://www.foodsafety.ufl.edu. Accessed August 2000.

Notice to Readers

\section{Recall of Isoniazid Used for Antimicrobial Susceptibility Testing for Tuberculosis}

Becton Dickinson Biosciences (Sparks, Maryland) has issued a voluntary recall of a lot of isoniazid [INH] (drug lot no. 9335260) used for antimicrobial susceptibility testing (AST) of Mycobacterium tuberculosis. The recalled INH lot was sold as components of BACTECTM* S.I.R.E. kits (lot nos. 9327296, 9342298, and 9327298) and as individual drug for reconstitution (BACTEC ${ }^{\mathrm{TM}}$ Isoniazid kit lot no. 9327297) during January 2000-August $25,2000$.

* Use of trade names and commercial sources is for identification only and does not constitute endorsement by CDC or the U.S. Department of Health and Human Services. 
Notices to Readers - Continued

The recall was issued following customer complaints and subsequent investigations by the manufacturer that found that vials of streptomycin may have been labeled inadvertently as the recalled lot of INH. A second lot of INH (drug lot no. 0077261) that was implicated initially is no longer involved in the recall. In the original complaint involving lot no. 0077261 , the incorrect lot number was reported to the manufacturer. This recall does not affect other sources of INH used for AST or for therapeutic purposes.

Laboratories that perform AST for M. tuberculosis should identify all isolates on which INH AST was performed with the recalled lot of INH. The results of tests with recalled INH are unreliable, potentially yielding falsely susceptible or falsely resistent results. These test results should be confirmed by a second test using nonrecalled INH on the same isolate or on a subsequent isolate obtained from the patient. Clinicians caring for patients with isolates requiring repeat testing should be notified of the recall and the possibility of erroneous INH AST results. If necessary, laboratories should consult with clinicians to prioritize repeat INH AST testing as follows: 1) immediately retest isolates from patients who have not responded to antituberculosis therapy as expected; 2) retest isolates for which any other first-line antituberculosis drug resistance was observed; 3) retest isolates from patients still receiving induction phase therapy; and 4) retest remaining isolates for which INH AST is unreliable.

Clinicians and patients using the standard 6-month four-drug regimen for tuberculosis (1) should be reassured because 1) in the United States, most patients are treated successfully with this regimen; 2 ) most patients are infected with strains of $M$. tuberculosis that are susceptible to all first-line antituberculosis drugs (2); and 3) results from controlled clinical trials indicate that this regimen is effective for patients infected with INH monoresistant $M$. tuberculosis (3). Therefore, patients who have completed this regimen and who have been discharged as cured before repeat AST results are available do not need additional drug therapy even if INH resistance is subsequently identified. Patients found to have INH monoresistant organisms after induction therapy is complete (e.g., during continuation phase of therapy with INH and rifampin) should be evaluated for treatment failure clinically and with cultures. Patients with an acceptable clinical course and no evidence of treatment failure could complete the continuation phase with INH and rifampin. In both instances, patients should be screened clinically for recurrent tuberculosis at 3,6, and 12 months after completion of therapy and, if relapse is suspected, cultures should be obtained.

Patients who are identified as infected with INH monoresistant organisms before the induction phase of therapy is completed may be treated with a combination of rifampin, pyrazinamide, and ethambutol (or streptomycin) for 6 months. INH also may be included if repeat AST is resistant to INH at low levels (e.g., $0.1 \mu \mathrm{g} / \mathrm{mL}$ BACTEC ${ }^{T M}$ media, or $0.2 \mu \mathrm{g} / \mathrm{mL}$ $7 \mathrm{H} 10$ media) but is not resistant at high levels (e.g., $0.4 \mu \mathrm{g} / \mathrm{mL}$ BACTEC ${ }^{\mathrm{TM}}$ media, or $1 \mu \mathrm{g} / \mathrm{mL}$ 7H10 media). Antituberculosis therapy and monitoring should be individualized for patients treated with other regimens, for patients who have not responded to therapy as expected, or for patients infected with $M$. tuberculosis strains resistant to one or more drugs in addition to INH. Patients with unrecognized INH monoresistance who were treated with the two-drug regimen of INH and rifampin and those treated initially with $\mathrm{INH}$, rifampin, and pyrazinamide are at increased risk for treatment failure and/or relapse after treatment, possibly associated with acquired rifampin resistance. If a change in the treatment regimen is considered necessary, the initial regimen should be augmented with at least two additional drugs to which the patient's $M$. tuberculosis isolate has been proven susceptible and, if possible, which the patient has not received previously. 
Notices to Readers - Continued

\section{References}

1. Bass JB, Farer LS, Hopewell R, et al. Treatment of tuberculosis and tuberculosis infection in adults and children. Am J Respir Crit Care Med 1994;149:1359-74.

2. Moore M, Onorato IM, McCray E, Castro KG. Trends in drug-resistant tuberculosis in the United States, 1993-1996. JAMA 1997;278:833-7.

3. Mitchison DA, Nunn AJ. Influence of initial drug resistance on the response to shortcourse chemotherapy of pulmonary tuberculosis. Am Rev Respir Dis 1986;133:423-30.

Notice to Readers

\section{Drive Safely Work Week — September 11-15, 2000}

The Network of Employers for Traffic Safety (NETS), a nonprofit organization comprising corporate, state, and federal partners, is sponsoring the fourth annual Drive Safely Work Week during September 11-15, 2000. Unintentional injuries are the leading cause of death in the United States for persons aged 1-44 years and accounted for approximately 97,000 deaths among persons of all ages in 1997 (1). In 1998, approximately 41,000 persons died on U.S. highways and another 3.2 million suffered nonfatal injuries (2).

Highway fatalities have decreased substantially since $1966(n=50,984)$, and the fatality rate per mile of travel has decreased more than threefold (from 5.5 in 1966 to 1.6 in 1998) (3). However, minimal changes have occurred in the numbers of fatalities and the fatality rate per mile from 1994 to 1998. Although most injuries and fatalities in 1998 were to vehicle occupants, pedestrians accounted for 5220 of the fatalities and 69,000 of the injuries (4). Motor-vehicle crashes also are the leading cause of occupational injury deaths, accounting for approximately 16,000 deaths in workers from 1980 to 1992, or $20 \%$ of all fatal workplace injuries over this period $(5)$.

The national campaign to prevent motor-vehicle crashes includes a "toolkit" that contains information, posters, and suggested programs that employers or other groups can use to address five major traffic safety issues: safety belt use, aggressive driving, driver inattention, sharing the road with trucks, and impaired driving. The materials are not dated and may be used throughout the year.

Additional information about NETS and purchasing the toolkit (cost: \$25) is available on the World-Wide Web, http://www.trafficsafety.org, ${ }^{*}$ or telephone, (202) 452-6005. Additional information about motor-vehicle-related injuries is available from the $\mathrm{Na}$ tional Highway Traffic Safety Administration at http://www.nhtsa.dot.gov. Information about occupational transportation injuries is available from CDC's National Institute for Occupational Safety and Health at http://www.cdc.gov/niosh.

\section{References}

1. National Center for Health Statistics. Deaths: final data for 1997. National Vital Statistics Reports, vol. 47, no. 19. Hyattsville, Maryland: US Department of Health and Human Services, CDC, National Center for Health Statistics, 1999.

2. National Highway Traffic Safety Administration. Traffic safety facts, 1998: overview. Washington, DC: US Department of Transportation, 1999 (HS 808 956).

* References to sites of non-CDC organizations on the World-Wide Web are provided as a service to $M M W R$ readers and do not constitute or imply endorsement of these organizations or their programs by CDC or the U.S. Department of Health and Human Services. CDC is not responsible for the content of pages found at these sites. 
FIGURE I. Selected notifiable disease reports, United States, comparison of provisional 4-week totals ending August 26, 2000, with historical data

DISEASE DECREASE

Hepatitis A

Hepatitis B

Hepatitis C; Non-A, Non-B

Legionellosis

Measles, Total

Meningococcal Infections

Mumps

Pertussis

Rubella
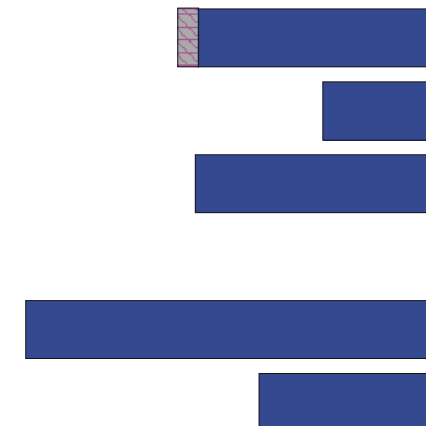

INCREASE

CASES CURRENT 4 WEEKS

610

359

\section{Ratio (Log Scale)*}

Beyond Historical Limits

${ }^{*}$ Ratio of current 4-week total to mean of 15 4-week totals (from previous, comparable, and subsequent 4 -week periods for the past 5 years). The point where the hatched area begins is based on the mean and two standard deviations of these 4-week totals.

\section{TABLE I. Summary of provisional cases of selected notifiable diseases,} United States, cumulative, week ending August 26, 2000 (34th Week)

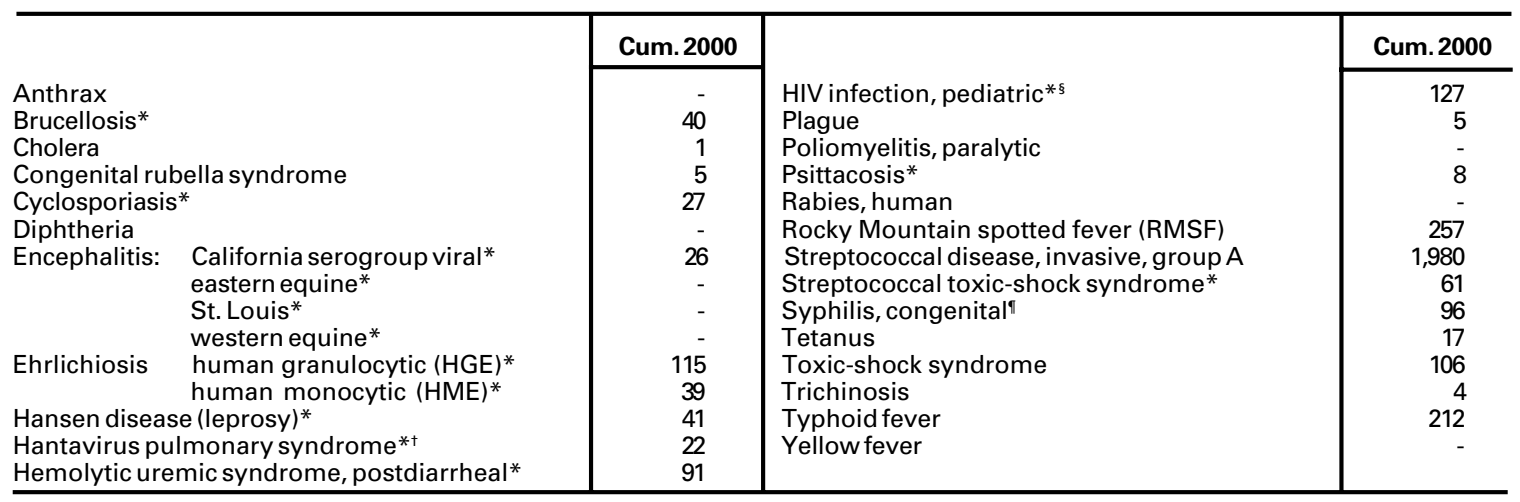

-: No reported cases.

* Not notifiable in all states.

+ Updated weekly from reports to the Division of Viral and Rickettsial Diseases, National Center for Infectious Diseases (NCID).

¿ Updated monthly from reports to the Division of HIV/AIDS Prevention - Surveillance and Epidemiology, National Center for HIV

STD, and TB Prevention (NCHSTP). Last update July 30, 2000.

I Updated from reports to the Division of STD Prevention, NCHSTP. 
TABLE II. Provisional cases of selected notifiable diseases, United States, weeks ending August 26, 2000, and August 28, 1999 (34th Week)

\begin{tabular}{|c|c|c|c|c|c|c|c|c|c|c|}
\hline \multirow[b]{3}{*}{ Reporting Area } & \multirow{2}{*}{\multicolumn{2}{|c|}{ AIDS }} & \multirow{2}{*}{\multicolumn{2}{|c|}{ Chlamydia $^{\dagger}$}} & \multirow{2}{*}{\multicolumn{2}{|c|}{ Cryptosporidiosis }} & \multicolumn{4}{|c|}{ Escherichia coli 0157:H7* } \\
\hline & & & & & & & \multicolumn{2}{|c|}{ NETSS } & \multicolumn{2}{|c|}{ PHLIS } \\
\hline & $\begin{array}{l}\text { Cum. } \\
2000^{s}\end{array}$ & $\begin{array}{c}\text { Cum. } \\
1999\end{array}$ & $\begin{array}{l}\text { Cum. } \\
2000\end{array}$ & $\begin{array}{c}\text { Cum. } \\
1999\end{array}$ & $\begin{array}{c}\text { Cum. } \\
2000\end{array}$ & $\begin{array}{c}\text { Cum. } \\
1999\end{array}$ & $\begin{array}{l}\text { Cum. } \\
2000\end{array}$ & $\begin{array}{c}\text { Cum. } \\
1999\end{array}$ & $\begin{array}{c}\text { Cum. } \\
2000\end{array}$ & $\begin{array}{c}\text { Cum. } \\
1999\end{array}$ \\
\hline UNITED STATES & 23,669 & 28,406 & 409,447 & 429,493 & 1,027 & 1,407 & 2,469 & 1,719 & 1,537 & 1,591 \\
\hline $\begin{array}{l}\text { NEW ENGLAND } \\
\text { Maine } \\
\text { N.H. } \\
\text { Vt. } \\
\text { Mass. } \\
\text { R.I. } \\
\text { Conn. }\end{array}$ & $\begin{array}{r}1,335 \\
20 \\
22 \\
11 \\
852 \\
55 \\
375\end{array}$ & $\begin{array}{r}1,502 \\
44 \\
33 \\
11 \\
987 \\
74 \\
353\end{array}$ & $\begin{array}{r}13,795 \\
905 \\
649 \\
352 \\
6,178 \\
1,570 \\
4,141\end{array}$ & $\begin{array}{r}13,821 \\
744 \\
639 \\
313 \\
5,921 \\
1,506 \\
4,698\end{array}$ & $\begin{array}{r}51 \\
12 \\
9 \\
17 \\
11 \\
2 \\
-\end{array}$ & $\begin{array}{r}96 \\
17 \\
9 \\
18 \\
41 \\
- \\
11\end{array}$ & $\begin{array}{r}232 \\
17 \\
22 \\
25 \\
101 \\
11 \\
56\end{array}$ & $\begin{array}{r}252 \\
20 \\
23 \\
20 \\
112 \\
19 \\
58\end{array}$ & $\begin{array}{r}217 \\
19 \\
22 \\
25 \\
89 \\
10 \\
52\end{array}$ & $\begin{array}{r}243 \\
- \\
23 \\
12 \\
118 \\
21 \\
69\end{array}$ \\
\hline $\begin{array}{l}\text { MID. ATLANTIC } \\
\text { Upstate N.Y. } \\
\text { N.Y. City } \\
\text { N.J. } \\
\text { Pa. }\end{array}$ & $\begin{array}{r}5,487 \\
572 \\
2,971 \\
1,116 \\
828\end{array}$ & $\begin{array}{r}7,188 \\
890 \\
3,734 \\
1,365 \\
1,199\end{array}$ & $\begin{array}{r}35,519 \\
N \\
14,822 \\
5,049 \\
15,648\end{array}$ & $\begin{array}{r}43,941 \\
N \\
18,328 \\
7,974 \\
17,639\end{array}$ & $\begin{array}{r}89 \\
57 \\
8 \\
4 \\
20\end{array}$ & $\begin{array}{r}258 \\
79 \\
148 \\
18 \\
13\end{array}$ & $\begin{array}{r}250 \\
179 \\
7 \\
64 \\
\mathrm{~N}\end{array}$ & $\begin{array}{r}131 \\
85 \\
12 \\
34 \\
\mathrm{~N}\end{array}$ & $\begin{array}{r}106 \\
38 \\
7 \\
31 \\
30\end{array}$ & $\begin{array}{r}75 \\
- \\
14 \\
47 \\
14\end{array}$ \\
\hline $\begin{array}{l}\text { E.N. CENTRAL } \\
\text { Ohio } \\
\text { Ind. } \\
\text { Ill. } \\
\text { Mich. } \\
\text { Wis. }\end{array}$ & $\begin{array}{r}2,282 \\
360 \\
217 \\
1,295 \\
297 \\
113\end{array}$ & $\begin{array}{r}1,963 \\
293 \\
244 \\
928 \\
401 \\
97\end{array}$ & $\begin{array}{r}65,733 \\
16,807 \\
8,341 \\
16,422 \\
16,571 \\
7,592\end{array}$ & $\begin{array}{r}71,676 \\
19,427 \\
7,660 \\
21,531 \\
13,851 \\
9,207\end{array}$ & $\begin{array}{r}225 \\
64 \\
19 \\
7 \\
52 \\
83\end{array}$ & $\begin{array}{r}362 \\
30 \\
21 \\
52 \\
31 \\
228\end{array}$ & $\begin{array}{r}483 \\
136 \\
81 \\
116 \\
73 \\
77\end{array}$ & $\begin{array}{r}336 \\
124 \\
43 \\
103 \\
66 \\
\mathrm{~N}\end{array}$ & $\begin{array}{r}191 \\
44 \\
54 \\
- \\
54 \\
39\end{array}$ & $\begin{array}{r}311 \\
111 \\
32 \\
79 \\
51 \\
38\end{array}$ \\
\hline $\begin{array}{l}\text { W.N. CENTRAL } \\
\text { Minn. } \\
\text { lowa } \\
\text { Mo. } \\
\text { N. Dak. } \\
\text { S. Dak. } \\
\text { Nebr. } \\
\text { Kans. }\end{array}$ & $\begin{array}{r}575 \\
102 \\
59 \\
284 \\
2 \\
4 \\
38 \\
86\end{array}$ & $\begin{array}{r}667 \\
114 \\
56 \\
341 \\
4 \\
13 \\
43 \\
96\end{array}$ & $\begin{array}{r}22,959 \\
4,467 \\
3,160 \\
8,049 \\
352 \\
1,147 \\
2,180 \\
3,604\end{array}$ & $\begin{array}{r}24,232 \\
4,922 \\
2,826 \\
8,681 \\
590 \\
1,021 \\
2,186 \\
4,006\end{array}$ & $\begin{array}{r}132 \\
21 \\
40 \\
18 \\
7 \\
9 \\
32 \\
5\end{array}$ & $\begin{array}{r}97 \\
13 \\
37 \\
15 \\
12 \\
5 \\
13 \\
2\end{array}$ & $\begin{array}{r}423 \\
100 \\
128 \\
93 \\
14 \\
33 \\
38 \\
17\end{array}$ & $\begin{array}{r}330 \\
103 \\
68 \\
26 \\
8 \\
34 \\
70 \\
21\end{array}$ & $\begin{array}{r}326 \\
95 \\
76 \\
67 \\
15 \\
30 \\
32 \\
11\end{array}$ & $\begin{array}{r}376 \\
132 \\
55 \\
39 \\
13 \\
43 \\
87 \\
7\end{array}$ \\
\hline $\begin{array}{l}\text { S. ATLANTIC } \\
\text { Del. } \\
\text { Md. } \\
\text { D.C. } \\
\text { Va. } \\
\text { W. Va. } \\
\text { N.C. } \\
\text { S.C. } \\
\text { Ga. } \\
\text { Fla. }\end{array}$ & $\begin{array}{r}6,331 \\
111 \\
710 \\
448 \\
418 \\
39 \\
394 \\
509 \\
704 \\
2,998\end{array}$ & $\begin{array}{r}7,774 \\
96 \\
886 \\
276 \\
500 \\
40 \\
553 \\
706 \\
1,089 \\
3,628\end{array}$ & $\begin{array}{r}83,921 \\
1,875 \\
8,410 \\
2,136 \\
10,307 \\
1,177 \\
14,390 \\
7,756 \\
16,797 \\
21,073\end{array}$ & $\begin{array}{r}91,841 \\
1,779 \\
8,518 \\
\mathrm{~N} \\
9,771 \\
1,156 \\
14,811 \\
11,869 \\
23,091 \\
20,846\end{array}$ & $\begin{array}{r}228 \\
5 \\
9 \\
8 \\
8 \\
3 \\
17 \\
- \\
84 \\
94\end{array}$ & $\begin{array}{r}214 \\
- \\
11 \\
6 \\
12 \\
- \\
6 \\
- \\
95 \\
84\end{array}$ & $\begin{array}{r}218 \\
- \\
15 \\
- \\
43 \\
10 \\
48 \\
15 \\
36 \\
51\end{array}$ & $\begin{array}{r}185 \\
6 \\
12 \\
- \\
44 \\
9 \\
40 \\
16 \\
17 \\
41\end{array}$ & $\begin{array}{r}150 \\
- \\
1 \\
U \\
38 \\
7 \\
44 \\
12 \\
23 \\
25\end{array}$ & $\begin{array}{r}129 \\
3 \\
- \\
U \\
42 \\
4 \\
44 \\
14 \\
1 \\
21\end{array}$ \\
\hline $\begin{array}{l}\text { E.S. CENTRAL } \\
\text { Ky. } \\
\text { Tenn. } \\
\text { Ala. } \\
\text { Miss. }\end{array}$ & $\begin{array}{r}1,128 \\
128 \\
461 \\
304 \\
235\end{array}$ & $\begin{array}{r}1,325 \\
174 \\
533 \\
334 \\
284\end{array}$ & $\begin{array}{r}30,771 \\
5,144 \\
9,221 \\
10,062 \\
6,344\end{array}$ & $\begin{array}{r}30,107 \\
4,968 \\
9,176 \\
8,217 \\
7,746\end{array}$ & $\begin{array}{r}36 \\
5 \\
9 \\
12 \\
10\end{array}$ & $\begin{array}{r}17 \\
5 \\
6 \\
4 \\
2\end{array}$ & $\begin{array}{r}84 \\
25 \\
39 \\
5 \\
15\end{array}$ & $\begin{array}{r}88 \\
22 \\
41 \\
17 \\
8\end{array}$ & $\begin{array}{r}65 \\
24 \\
30 \\
3 \\
8\end{array}$ & $\begin{array}{r}64 \\
15 \\
28 \\
17 \\
4\end{array}$ \\
\hline $\begin{array}{l}\text { W.S. CENTRAL } \\
\text { Ark. } \\
\text { La. } \\
\text { Okla. } \\
\text { Tex. }\end{array}$ & $\begin{array}{r}2,418 \\
112 \\
381 \\
182 \\
1,743\end{array}$ & $\begin{array}{r}3,174 \\
122 \\
590 \\
94 \\
2,368\end{array}$ & $\begin{array}{r}62,352 \\
3,287 \\
12,137 \\
5,028 \\
41,900\end{array}$ & $\begin{array}{r}59,989 \\
3,872 \\
10,684 \\
5,450 \\
39,983\end{array}$ & $\begin{array}{r}44 \\
5 \\
8 \\
4 \\
27\end{array}$ & $\begin{array}{r}52 \\
1 \\
22 \\
5 \\
24\end{array}$ & $\begin{array}{r}117 \\
47 \\
4 \\
10 \\
56\end{array}$ & $\begin{array}{r}68 \\
9 \\
9 \\
15 \\
35\end{array}$ & $\begin{array}{r}162 \\
30 \\
36 \\
7 \\
89\end{array}$ & $\begin{array}{r}80 \\
7 \\
11 \\
12 \\
50\end{array}$ \\
\hline $\begin{array}{l}\text { MOUNTAIN } \\
\text { Mont. } \\
\text { Idaho } \\
\text { Wyo. } \\
\text { Colo. } \\
\text { N. Mex. } \\
\text { Ariz. } \\
\text { Utah } \\
\text { Nev. }\end{array}$ & $\begin{array}{r}862 \\
9 \\
16 \\
7 \\
199 \\
88 \\
265 \\
90 \\
188\end{array}$ & $\begin{array}{r}1,076 \\
5 \\
15 \\
7 \\
207 \\
65 \\
516 \\
102 \\
159\end{array}$ & $\begin{array}{r}24,610 \\
960 \\
1,192 \\
474 \\
7,415 \\
2,974 \\
7,706 \\
1,506 \\
2,383\end{array}$ & $\begin{array}{r}22,532 \\
975 \\
1,127 \\
502 \\
4,866 \\
3,324 \\
8,290 \\
1,370 \\
2,078\end{array}$ & $\begin{array}{r}57 \\
8 \\
3 \\
4 \\
18 \\
6 \\
5 \\
10 \\
3\end{array}$ & $\begin{array}{r}65 \\
10 \\
7 \\
- \\
9 \\
24 \\
10 \\
N \\
5\end{array}$ & $\begin{array}{r}276 \\
26 \\
41 \\
11 \\
106 \\
16 \\
35 \\
34 \\
7\end{array}$ & $\begin{array}{r}154 \\
9 \\
18 \\
7 \\
54 \\
7 \\
23 \\
24 \\
12\end{array}$ & $\begin{array}{r}140 \\
- \\
- \\
2 \\
61 \\
10 \\
26 \\
41 \\
-\end{array}$ & $\begin{array}{r}122 \\
- \\
10 \\
13 \\
37 \\
3 \\
14 \\
32 \\
13\end{array}$ \\
\hline $\begin{array}{l}\text { PACIFIC } \\
\text { Wash. } \\
\text { Oreg. } \\
\text { Calif. } \\
\text { Alaska } \\
\text { Hawaii }\end{array}$ & $\begin{array}{r}3,251 \\
301 \\
106 \\
2,749 \\
12 \\
83\end{array}$ & $\begin{array}{r}3,737 \\
213 \\
136 \\
3,315 \\
13 \\
60\end{array}$ & $\begin{array}{r}69,787 \\
8,089 \\
3,285 \\
55,226 \\
1,531 \\
1,656\end{array}$ & $\begin{array}{r}71,354 \\
7,707 \\
4,083 \\
56,238 \\
1,223 \\
2,103\end{array}$ & $\begin{array}{r}165 \\
N \\
10 \\
155 \\
- \\
-\end{array}$ & $\begin{array}{r}246 \\
N \\
79 \\
167 \\
- \\
-\end{array}$ & $\begin{array}{r}386 \\
125 \\
62 \\
172 \\
19 \\
8\end{array}$ & $\begin{array}{r}175 \\
58 \\
38 \\
70 \\
- \\
9\end{array}$ & $\begin{array}{r}180 \\
97 \\
63 \\
12 \\
1 \\
7\end{array}$ & $\begin{array}{r}191 \\
77 \\
44 \\
62 \\
- \\
8\end{array}$ \\
\hline $\begin{array}{l}\text { Guam } \\
\text { P.R. } \\
\text { V.I. } \\
\text { Amer. Samoa } \\
\text { C.N.M.I. }\end{array}$ & $\begin{array}{r}14 \\
710 \\
24 \\
- \\
-\end{array}$ & $\begin{array}{r}11 \\
937 \\
19 \\
- \\
-\end{array}$ & $\begin{array}{r}- \\
1,060 \\
- \\
- \\
-\end{array}$ & $\begin{array}{r}{ }_{U}^{298} \\
\cup\end{array}$ & $\begin{array}{l}- \\
- \\
- \\
- \\
-\end{array}$ & $\begin{array}{l}- \\
\cup \\
\cup\end{array}$ & $\begin{array}{l}N \\
4 \\
- \\
- \\
-\end{array}$ & $\begin{array}{l}N \\
5 \\
U \\
U \\
U\end{array}$ & $\begin{array}{l}U \\
U \\
U \\
U\end{array}$ & $\begin{array}{l}U \\
\cup \\
U\end{array}$ \\
\hline
\end{tabular}

$\mathrm{N}$ : Not notifiable. $\quad$ U: Unavailable. $\quad-:$ No reported cases.

C.N.M.I.: Commonwealth of Northern Mariana Islands. * Individual cases can be reported through both the National Electronic Telecommunications System for Surveillance (NETSS) and the Public Health Laboratory Information System (PHLIS).

+ Chlamydia refers to genital infections caused by $C$. trachomatis. Totals reported to the Division of STD Prevention, NCHSTP.

$\S$ Updated monthly from reports to the Division of HIV/AIDS Prevention - Surveillance and Epidemiology, National Center for HIV, STD, and TB Prevention. Last update July 30, 2000. 
TABLE II. (Cont'd) Provisional cases of selected notifiable diseases, United States, weeks ending August 26, 2000, and August 28, 1999 (34th Week)

\begin{tabular}{|c|c|c|c|c|c|c|c|c|}
\hline \multirow[b]{2}{*}{ Reporting Area } & \multicolumn{2}{|c|}{ Gonorrhea } & \multicolumn{2}{|c|}{$\begin{array}{c}\text { Hepatitis C; } \\
\text { Non-A, Non-B }\end{array}$} & \multicolumn{2}{|c|}{ Legionellosis } & \multicolumn{2}{|c|}{$\begin{array}{l}\text { Lyme } \\
\text { Disease }\end{array}$} \\
\hline & $\begin{array}{l}\text { Cum. } \\
2000\end{array}$ & $\begin{array}{l}\text { Cum. } \\
1999\end{array}$ & $\begin{array}{l}\text { Cum. } \\
2000\end{array}$ & $\begin{array}{c}\text { Cum. } \\
1999\end{array}$ & $\begin{array}{l}\text { Cum. } \\
2000\end{array}$ & $\begin{array}{c}\text { Cum. } \\
1999 \\
\end{array}$ & $\begin{array}{l}\text { Cum. } \\
2000 \\
\end{array}$ & $\begin{array}{r}\text { Cum. } \\
1999\end{array}$ \\
\hline UNITED STATES & 212,832 & 231,851 & 1,981 & 1,760 & 549 & 585 & 6,371 & 9,136 \\
\hline $\begin{array}{l}\text { NEW ENGLAND } \\
\text { Maine } \\
\text { N.H. } \\
\text { Vt. } \\
\text { Mass. } \\
\text { R.I. } \\
\text { Conn. }\end{array}$ & $\begin{array}{r}3,841 \\
52 \\
68 \\
41 \\
1,665 \\
388 \\
1,627\end{array}$ & $\begin{array}{r}4,201 \\
42 \\
71 \\
35 \\
1,646 \\
381 \\
2,026\end{array}$ & $\begin{array}{r}30 \\
2 \\
- \\
3 \\
20 \\
5 \\
-\end{array}$ & $\begin{array}{r}13 \\
2 \\
- \\
5 \\
3 \\
3 \\
-\end{array}$ & $\begin{array}{r}24 \\
2 \\
2 \\
3 \\
9 \\
3 \\
5\end{array}$ & $\begin{array}{r}39 \\
3 \\
4 \\
8 \\
12 \\
3 \\
9\end{array}$ & $\begin{array}{r}1,387 \\
- \\
35 \\
9 \\
536 \\
213 \\
594\end{array}$ & $\begin{array}{r}2,861 \\
22 \\
4 \\
9 \\
605 \\
281 \\
1,940\end{array}$ \\
\hline $\begin{array}{l}\text { MID. ATLANTIC } \\
\text { Upstate N.Y. } \\
\text { N.Y. City } \\
\text { N.J. } \\
\text { Pa. }\end{array}$ & $\begin{array}{r}21,306 \\
4,173 \\
5,949 \\
3,890 \\
7,294\end{array}$ & $\begin{array}{r}25,895 \\
4,200 \\
8,499 \\
4,927 \\
8,269\end{array}$ & $\begin{array}{r}414 \\
47 \\
- \\
342 \\
25\end{array}$ & $\begin{array}{r}83 \\
39 \\
- \\
- \\
44\end{array}$ & $\begin{array}{r}118 \\
46 \\
- \\
8 \\
64\end{array}$ & $\begin{array}{r}135 \\
34 \\
17 \\
12 \\
72\end{array}$ & $\begin{array}{r}3,785 \\
1,945 \\
7 \\
874 \\
959\end{array}$ & $\begin{array}{r}4,581 \\
2,452 \\
110 \\
1,064 \\
955\end{array}$ \\
\hline $\begin{array}{l}\text { E.N. CENTRAL } \\
\text { Ohio } \\
\text { Ind. } \\
\text { III. } \\
\text { Mich. } \\
\text { Wis. }\end{array}$ & $\begin{array}{r}39,487 \\
10,168 \\
3,871 \\
10,786 \\
11,509 \\
3,153\end{array}$ & $\begin{array}{r}44,647 \\
11,568 \\
4,119 \\
14,925 \\
9,992 \\
4,043\end{array}$ & $\begin{array}{r}160 \\
7 \\
1 \\
10 \\
142 \\
-\end{array}$ & $\begin{array}{r}626 \\
1 \\
1 \\
38 \\
570 \\
16\end{array}$ & $\begin{array}{r}147 \\
66 \\
31 \\
8 \\
29 \\
13\end{array}$ & $\begin{array}{r}180 \\
54 \\
24 \\
25 \\
44 \\
33\end{array}$ & $\begin{array}{r}249 \\
68 \\
18 \\
11 \\
- \\
152\end{array}$ & $\begin{array}{r}498 \\
31 \\
14 \\
17 \\
11 \\
425\end{array}$ \\
\hline $\begin{array}{l}\text { W.N. CENTRAL } \\
\text { Minn. } \\
\text { lowa } \\
\text { Mo. } \\
\text { N. Dak. } \\
\text { S. Dak. } \\
\text { Nebr. } \\
\text { Kans. }\end{array}$ & $\begin{array}{r}10,160 \\
1,791 \\
664 \\
5,084 \\
15 \\
187 \\
826 \\
1,593\end{array}$ & $\begin{array}{r}10,528 \\
1,831 \\
682 \\
5,126 \\
59 \\
116 \\
996 \\
1,718\end{array}$ & $\begin{array}{r}439 \\
5 \\
1 \\
421 \\
- \\
- \\
3 \\
9\end{array}$ & $\begin{array}{r}138 \\
4 \\
- \\
132 \\
- \\
- \\
2 \\
-\end{array}$ & $\begin{array}{r}44 \\
3 \\
12 \\
23 \\
- \\
2 \\
1 \\
3\end{array}$ & $\begin{array}{r}33 \\
4 \\
9 \\
14 \\
- \\
2 \\
4 \\
-\end{array}$ & $\begin{array}{r}155 \\
85 \\
16 \\
38 \\
- \\
- \\
1 \\
15\end{array}$ & $\begin{array}{r}174 \\
82 \\
20 \\
51 \\
1 \\
- \\
10 \\
10\end{array}$ \\
\hline $\begin{array}{l}\text { S. ATLANTIC } \\
\text { Del. } \\
\text { Md. } \\
\text { D.C. } \\
\text { Va. } \\
\text { W. Va. } \\
\text { N.C. } \\
\text { S.C. } \\
\text { Ga. } \\
\text { Fla. }\end{array}$ & $\begin{array}{r}62,430 \\
1,091 \\
5,690 \\
1,676 \\
6,440 \\
366 \\
11,808 \\
9,988 \\
10,721 \\
14,650\end{array}$ & $\begin{array}{r}67,861 \\
1,110 \\
6,354 \\
2,428 \\
6,322 \\
389 \\
12,941 \\
8,180 \\
15,315 \\
14,822\end{array}$ & $\begin{array}{r}82 \\
- \\
13 \\
2 \\
3 \\
12 \\
13 \\
1 \\
2 \\
36\end{array}$ & $\begin{array}{r}115 \\
- \\
19 \\
- \\
10 \\
13 \\
28 \\
15 \\
1 \\
29\end{array}$ & $\begin{array}{r}113 \\
5 \\
42 \\
- \\
17 \\
\mathrm{~N} \\
9 \\
4 \\
6 \\
30\end{array}$ & $\begin{array}{r}76 \\
9 \\
15 \\
1 \\
17 \\
\mathrm{~N} \\
13 \\
7 \\
- \\
14\end{array}$ & $\begin{array}{r}656 \\
104 \\
374 \\
3 \\
95 \\
22 \\
32 \\
3 \\
- \\
23\end{array}$ & $\begin{array}{r}819 \\
50 \\
609 \\
3 \\
76 \\
14 \\
52 \\
4 \\
- \\
11\end{array}$ \\
\hline $\begin{array}{l}\text { E.S. CENTRAL } \\
\text { Ky. } \\
\text { Tenn. } \\
\text { Ala. } \\
\text { Miss. }\end{array}$ & $\begin{array}{r}22,343 \\
2,237 \\
7,335 \\
7,781 \\
4,990\end{array}$ & $\begin{array}{r}23,938 \\
2,210 \\
7,422 \\
7,289 \\
7,017\end{array}$ & $\begin{array}{r}303 \\
28 \\
66 \\
7 \\
202\end{array}$ & $\begin{array}{r}198 \\
12 \\
69 \\
1 \\
116\end{array}$ & $\begin{array}{r}19 \\
10 \\
7 \\
2 \\
-\end{array}$ & $\begin{array}{r}34 \\
13 \\
16 \\
3 \\
2\end{array}$ & $\begin{array}{r}28 \\
4 \\
18 \\
6 \\
-\end{array}$ & $\begin{array}{r}67 \\
10 \\
38 \\
16 \\
3\end{array}$ \\
\hline $\begin{array}{l}\text { W.S. CENTRAL } \\
\text { Ark. } \\
\text { La. } \\
\text { Okla. } \\
\text { Tex. }\end{array}$ & $\begin{array}{r}32,437 \\
1,762 \\
8,792 \\
2,176 \\
19,707\end{array}$ & $\begin{array}{r}34,153 \\
1,980 \\
8,452 \\
2,694 \\
21,027\end{array}$ & $\begin{array}{r}296 \\
9 \\
183 \\
6 \\
98\end{array}$ & $\begin{array}{r}327 \\
19 \\
226 \\
13 \\
69\end{array}$ & $\begin{array}{r}12 \\
- \\
8 \\
2 \\
2\end{array}$ & $\begin{array}{l}6 \\
1 \\
3 \\
2 \\
-\end{array}$ & $\begin{array}{r}14 \\
4 \\
2 \\
- \\
8\end{array}$ & $\begin{array}{r}36 \\
4 \\
6 \\
7 \\
19\end{array}$ \\
\hline $\begin{array}{l}\text { MOUNTAIN } \\
\text { Mont. } \\
\text { Idaho } \\
\text { Wyo. } \\
\text { Colo. } \\
\text { N. Mex. } \\
\text { Ariz. } \\
\text { Utah } \\
\text { Nev. }\end{array}$ & $\begin{array}{r}6,386 \\
28 \\
59 \\
34 \\
1,982 \\
632 \\
2,612 \\
156 \\
883\end{array}$ & $\begin{array}{r}6,254 \\
26 \\
54 \\
16 \\
1,570 \\
655 \\
2,967 \\
129 \\
837\end{array}$ & $\begin{array}{r}130 \\
4 \\
3 \\
73 \\
16 \\
11 \\
13 \\
1 \\
9\end{array}$ & $\begin{array}{r}124 \\
4 \\
6 \\
35 \\
23 \\
22 \\
21 \\
5 \\
8\end{array}$ & $\begin{array}{r}25 \\
1 \\
4 \\
1 \\
9 \\
1 \\
5 \\
4 \\
-\end{array}$ & $\begin{array}{r}31 \\
- \\
- \\
- \\
8 \\
1 \\
5 \\
11 \\
6\end{array}$ & $\begin{array}{r}12 \\
- \\
2 \\
1 \\
6 \\
- \\
- \\
1 \\
2\end{array}$ & $\begin{array}{r}11 \\
- \\
1 \\
3 \\
2 \\
1 \\
- \\
2 \\
2\end{array}$ \\
\hline $\begin{array}{l}\text { PACIFIC } \\
\text { Wash. } \\
\text { Oreg. } \\
\text { Calif. } \\
\text { Alaska } \\
\text { Hawaii }\end{array}$ & $\begin{array}{r}14,442 \\
1,410 \\
446 \\
12,156 \\
204 \\
226\end{array}$ & $\begin{array}{r}14,374 \\
1,329 \\
583 \\
11,968 \\
200 \\
294\end{array}$ & $\begin{array}{r}127 \\
19 \\
21 \\
85 \\
- \\
2\end{array}$ & $\begin{array}{r}136 \\
12 \\
12 \\
112 \\
- \\
-\end{array}$ & $\begin{array}{r}47 \\
15 \\
N \\
32 \\
- \\
-\end{array}$ & $\begin{array}{r}51 \\
10 \\
N \\
40 \\
1 \\
-\end{array}$ & $\begin{array}{r}85 \\
4 \\
4 \\
75 \\
2 \\
N\end{array}$ & $\begin{array}{r}89 \\
4 \\
10 \\
75 \\
- \\
N\end{array}$ \\
\hline $\begin{array}{l}\text { Guam } \\
\text { P.R. } \\
\text { V.I. } \\
\text { Amer. Samoa } \\
\text { C.N.M.I. }\end{array}$ & $\begin{array}{r}398 \\
- \\
- \\
-\end{array}$ & $\begin{array}{r}38 \\
215 \\
U \\
U \\
U\end{array}$ & $\begin{array}{l}- \\
1 \\
- \\
- \\
-\end{array}$ & $\begin{array}{l}1 \\
- \\
U \\
U \\
U\end{array}$ & $\begin{array}{l}- \\
1 \\
- \\
- \\
-\end{array}$ & $\begin{array}{l}- \\
\\
U \\
U\end{array}$ & $\begin{array}{l}- \\
\text { N } \\
- \\
- \\
-\end{array}$ & $\bigcup_{U}^{-}$ \\
\hline
\end{tabular}

$\mathrm{N}$ : Not notifiable.

U: Unavailable.

- : No reported cases. 
TABLE II. (Cont'd) Provisional cases of selected notifiable diseases, United States, weeks ending August 26, 2000, and August 28, 1999 (34th Week)

\begin{tabular}{|c|c|c|c|c|c|c|c|c|}
\hline \multirow[b]{3}{*}{ Reporting Area } & \multirow{2}{*}{\multicolumn{2}{|c|}{ Malaria }} & \multirow{2}{*}{\multicolumn{2}{|c|}{ Rabies, Animal }} & \multicolumn{4}{|c|}{ Salmonellosis* } \\
\hline & & & & & \multicolumn{2}{|c|}{ NETSS } & \multicolumn{2}{|c|}{ PHLIS } \\
\hline & $\begin{array}{l}\text { Cum. } \\
2000\end{array}$ & $\begin{array}{c}\text { Cum. } \\
1999\end{array}$ & $\begin{array}{l}\text { Cum. } \\
2000\end{array}$ & $\begin{array}{r}\text { Cum. } \\
1999\end{array}$ & $\begin{array}{l}\text { Cum. } \\
2000\end{array}$ & $\begin{array}{c}\text { Cum. } \\
1999\end{array}$ & $\begin{array}{l}\text { Cum. } \\
2000\end{array}$ & $\begin{array}{r}\text { Cum } \\
1999 \\
\end{array}$ \\
\hline UNITED STATES & 689 & 908 & 3,752 & 4,240 & 20,820 & 23,138 & 15,868 & 21,312 \\
\hline $\begin{array}{l}\text { NEW ENGLAND } \\
\text { Maine } \\
\text { N.H. } \\
\text { Vt. } \\
\text { Mass. } \\
\text { R.I. } \\
\text { Conn. }\end{array}$ & $\begin{array}{r}35 \\
4 \\
1 \\
2 \\
10 \\
5 \\
13\end{array}$ & $\begin{array}{r}33 \\
3 \\
2 \\
4 \\
13 \\
3 \\
8\end{array}$ & $\begin{array}{r}475 \\
91 \\
9 \\
41 \\
167 \\
38 \\
129\end{array}$ & $\begin{array}{r}556 \\
103 \\
30 \\
70 \\
123 \\
68 \\
162\end{array}$ & $\begin{array}{r}1,301 \\
91 \\
88 \\
83 \\
725 \\
83 \\
231\end{array}$ & $\begin{array}{r}1,406 \\
92 \\
90 \\
61 \\
776 \\
65 \\
322\end{array}$ & $\begin{array}{r}1,270 \\
68 \\
83 \\
76 \\
677 \\
89 \\
277\end{array}$ & $\begin{array}{r}1,461 \\
78 \\
93 \\
50 \\
790 \\
113 \\
337\end{array}$ \\
\hline $\begin{array}{l}\text { MID. ATLANTIC } \\
\text { Upstate N.Y. } \\
\text { N.Y. City } \\
\text { N.J. } \\
\text { Pa. }\end{array}$ & $\begin{array}{r}127 \\
45 \\
45 \\
18 \\
19\end{array}$ & $\begin{array}{r}251 \\
46 \\
136 \\
41 \\
28\end{array}$ & $\begin{array}{r}694 \\
479 \\
\cup \\
109 \\
106\end{array}$ & $\begin{array}{r}788 \\
567 \\
U \\
122 \\
99\end{array}$ & $\begin{array}{r}2,502 \\
743 \\
586 \\
548 \\
625\end{array}$ & $\begin{array}{r}3,107 \\
774 \\
932 \\
658 \\
743\end{array}$ & $\begin{array}{r}2,622 \\
827 \\
602 \\
393 \\
800\end{array}$ & $\begin{array}{r}3,192 \\
816 \\
928 \\
720 \\
728\end{array}$ \\
\hline $\begin{array}{l}\text { E.N. CENTRAL } \\
\text { Ohio } \\
\text { Ind. } \\
\text { III. } \\
\text { Mich. } \\
\text { Wis. }\end{array}$ & $\begin{array}{r}67 \\
14 \\
4 \\
22 \\
21 \\
6\end{array}$ & $\begin{array}{r}111 \\
17 \\
11 \\
48 \\
28 \\
7\end{array}$ & $\begin{array}{r}98 \\
29 \\
- \\
17 \\
47 \\
5\end{array}$ & $\begin{array}{r}95 \\
27 \\
- \\
5 \\
46 \\
17\end{array}$ & $\begin{array}{r}2,863 \\
770 \\
362 \\
806 \\
580 \\
345\end{array}$ & $\begin{array}{r}3,401 \\
755 \\
324 \\
1,098 \\
641 \\
583\end{array}$ & $\begin{array}{r}1,640 \\
453 \\
353 \\
1 \\
596 \\
237\end{array}$ & $\begin{array}{r}3,033 \\
683 \\
310 \\
1,057 \\
641 \\
342\end{array}$ \\
\hline $\begin{array}{l}\text { W.N. CENTRAL } \\
\text { Minn. } \\
\text { lowa } \\
\text { Mo. } \\
\text { N. Dak. } \\
\text { S. Dak. } \\
\text { Nebr. } \\
\text { Kans. }\end{array}$ & $\begin{array}{r}33 \\
13 \\
1 \\
6 \\
2 \\
- \\
5 \\
6\end{array}$ & $\begin{array}{r}48 \\
21 \\
12 \\
11 \\
- \\
- \\
- \\
4\end{array}$ & $\begin{array}{r}375 \\
59 \\
53 \\
28 \\
94 \\
65 \\
1 \\
75\end{array}$ & $\begin{array}{r}524 \\
75 \\
100 \\
18 \\
104 \\
140 \\
3 \\
84\end{array}$ & $\begin{array}{r}1,455 \\
313 \\
254 \\
461 \\
43 \\
58 \\
106 \\
220\end{array}$ & $\begin{array}{r}1,475 \\
395 \\
165 \\
462 \\
32 \\
69 \\
131 \\
221\end{array}$ & $\begin{array}{r}1,522 \\
413 \\
185 \\
572 \\
56 \\
65 \\
44 \\
187\end{array}$ & $\begin{array}{r}1,642 \\
509 \\
151 \\
571 \\
48 \\
91 \\
115 \\
157\end{array}$ \\
\hline $\begin{array}{l}\text { S. ATLANTIC } \\
\text { Del. } \\
\text { Md. } \\
\text { D.C. } \\
\text { Va. } \\
\text { W. Va. } \\
\text { N.C. } \\
\text { S.C. } \\
\text { Ga. } \\
\text { Fla. }\end{array}$ & $\begin{array}{r}195 \\
3 \\
67 \\
13 \\
37 \\
2 \\
16 \\
1 \\
4 \\
52\end{array}$ & $\begin{array}{r}226 \\
1 \\
68 \\
13 \\
51 \\
1 \\
15 \\
7 \\
21 \\
49\end{array}$ & $\begin{array}{r}371 \\
85 \\
376 \\
107 \\
222 \\
99\end{array}$ & $\begin{array}{r}344 \\
81 \\
296 \\
102 \\
124 \\
122\end{array}$ & $\begin{array}{r}4,603 \\
74 \\
536 \\
37 \\
631 \\
105 \\
607 \\
450 \\
773 \\
1,390\end{array}$ & $\begin{array}{r}4,834 \\
92 \\
541 \\
55 \\
850 \\
112 \\
719 \\
336 \\
687 \\
1,442\end{array}$ & $\begin{array}{r}2,954 \\
80 \\
462 \\
U \\
517 \\
93 \\
538 \\
347 \\
821 \\
96\end{array}$ & $\begin{array}{r}4,048 \\
108 \\
554 \\
U \\
754 \\
105 \\
837 \\
288 \\
1,013 \\
389\end{array}$ \\
\hline $\begin{array}{l}\text { E.S. CENTRAL } \\
\text { Ky. } \\
\text { Tenn. } \\
\text { Ala. } \\
\text { Miss. }\end{array}$ & $\begin{array}{r}28 \\
8 \\
6 \\
13 \\
1\end{array}$ & $\begin{array}{r}19 \\
6 \\
7 \\
5 \\
1\end{array}$ & $\begin{array}{r}128 \\
16 \\
68 \\
44 \\
-\end{array}$ & $\begin{array}{r}196 \\
31 \\
71 \\
94\end{array}$ & $\begin{array}{r}1,292 \\
239 \\
358 \\
367 \\
328\end{array}$ & $\begin{array}{r}1,275 \\
269 \\
331 \\
361 \\
314\end{array}$ & $\begin{array}{r}941 \\
171 \\
399 \\
307 \\
64\end{array}$ & $\begin{array}{r}926 \\
187 \\
385 \\
290 \\
64\end{array}$ \\
\hline $\begin{array}{l}\text { W.S. CENTRAL } \\
\text { Ark. } \\
\text { La. } \\
\text { Okla. } \\
\text { Tex. }\end{array}$ & $\begin{array}{l}8 \\
2 \\
2 \\
4 \\
-\end{array}$ & $\begin{array}{r}14 \\
2 \\
10 \\
2\end{array}$ & $\begin{array}{r}63 \\
20 \\
- \\
43\end{array}$ & $\begin{array}{r}321 \\
14 \\
7 \overline{-} \\
233\end{array}$ & $\begin{array}{r}1,687 \\
407 \\
115 \\
261 \\
904\end{array}$ & $\begin{array}{r}2,090 \\
311 \\
458 \\
258 \\
1,063\end{array}$ & $\begin{array}{r}2,399 \\
329 \\
368 \\
164 \\
1,538\end{array}$ & $\begin{array}{r}1,729 \\
120 \\
394 \\
213 \\
1,002\end{array}$ \\
\hline $\begin{array}{l}\text { MOUNTAIN } \\
\text { Mont. } \\
\text { Idaho } \\
\text { Wyo. } \\
\text { Colo. } \\
\text { N. Mex. } \\
\text { Ariz. } \\
\text { Utah } \\
\text { Nev. }\end{array}$ & $\begin{array}{r}35 \\
1 \\
2 \\
- \\
19 \\
- \\
5 \\
4 \\
4\end{array}$ & $\begin{array}{r}28 \\
4 \\
3 \\
1 \\
12 \\
2 \\
2 \\
3 \\
1\end{array}$ & $\begin{array}{r}171 \\
48 \\
8 \\
38 \\
- \\
16 \\
50 \\
9 \\
2\end{array}$ & $\begin{array}{r}135 \\
46 \\
- \\
32 \\
1 \\
6 \\
43 \\
4 \\
3\end{array}$ & $\begin{array}{r}1,821 \\
69 \\
87 \\
43 \\
500 \\
157 \\
461 \\
323 \\
181\end{array}$ & $\begin{array}{r}1,982 \\
39 \\
66 \\
35 \\
531 \\
275 \\
571 \\
337 \\
128\end{array}$ & $\begin{array}{r}1,308 \\
- \\
14 \\
451 \\
140 \\
420 \\
283\end{array}$ & $\begin{array}{r}1,767 \\
1 \\
63 \\
37 \\
513 \\
223 \\
526 \\
355 \\
49\end{array}$ \\
\hline $\begin{array}{l}\text { PACIFIC } \\
\text { Wash. } \\
\text { Oreg. } \\
\text { Calif. } \\
\text { Alaska } \\
\text { Hawaii }\end{array}$ & $\begin{array}{r}161 \\
16 \\
28 \\
114 \\
- \\
3\end{array}$ & $\begin{array}{r}178 \\
17 \\
15 \\
134 \\
1 \\
11\end{array}$ & $\begin{array}{r}185 \\
- \\
5 \\
159 \\
21 \\
-\end{array}$ & $\begin{array}{r}252 \\
- \\
1 \\
244 \\
7 \\
-\end{array}$ & $\begin{array}{r}3,296 \\
338 \\
208 \\
2,573 \\
38 \\
139\end{array}$ & $\begin{array}{r}3,568 \\
428 \\
315 \\
2,532 \\
34 \\
259\end{array}$ & $\begin{array}{r}1,212 \\
376 \\
253 \\
416 \\
23 \\
144\end{array}$ & $\begin{array}{r}3,514 \\
581 \\
345 \\
2,363 \\
18 \\
207\end{array}$ \\
\hline $\begin{array}{l}\text { Guam } \\
\text { P.R. } \\
\text { V.I. } \\
\text { Amer. Samoa } \\
\text { C.N.M.I. }\end{array}$ & $\begin{array}{l}- \\
- \\
- \\
-\end{array}$ & $\begin{array}{l}- \\
\bar{U} \\
U\end{array}$ & $\begin{array}{r}49 \\
- \\
-\end{array}$ & $\begin{array}{l}53 \\
U \\
U \\
U\end{array}$ & $\begin{array}{r}219 \\
- \\
- \\
-\end{array}$ & $\begin{array}{r}28 \\
367 \\
U \\
U\end{array}$ & $\begin{array}{l}U \\
U \\
U \\
U\end{array}$ & $\begin{array}{l}U \\
U \\
U \\
U\end{array}$ \\
\hline
\end{tabular}

$\mathrm{N}:$ Not notifiable. $\quad$ U: Unavailable.

$-:$ No reported cases.

* Individual cases can be reported through both the National Electronic Telecommunications System for Surveillance (NETSS) and the Public Health Laboratory Information System (PHLIS). 
TABLE II. (Cont'd) Provisional cases of selected notifiable diseases, United States, weeks ending August 26, 2000, and August 28, 1999 (34th Week)

\begin{tabular}{|c|c|c|c|c|c|c|c|c|}
\hline \multirow[b]{3}{*}{ Reporting Area } & \multicolumn{4}{|c|}{ Shigellosis* } & \multirow{2}{*}{\multicolumn{2}{|c|}{$\begin{array}{c}\text { Syphilis } \\
\text { (Primary \& Secondary) }\end{array}$}} & \multirow{2}{*}{\multicolumn{2}{|c|}{ Tuberculosis }} \\
\hline & \multicolumn{2}{|c|}{ NETSS } & \multicolumn{2}{|c|}{ PHLIS } & & & & \\
\hline & $\begin{array}{l}\text { Cum. } \\
2000\end{array}$ & $\begin{array}{l}\text { Cum. } \\
1999\end{array}$ & $\begin{array}{l}\text { Cum. } \\
2000\end{array}$ & $\begin{array}{c}\text { Cum. } \\
1999\end{array}$ & $\begin{array}{c}\text { Cum. } \\
2000\end{array}$ & $\begin{array}{c}\text { Cum. } \\
1999\end{array}$ & $\begin{array}{l}\text { Cum. } \\
2000\end{array}$ & $\begin{array}{c}\text { Cum. } \\
1999\end{array}$ \\
\hline UNITED STATES & 11,954 & 9,692 & 6,207 & 5,799 & 3,805 & 4,385 & 7,460 & 10,185 \\
\hline $\begin{array}{l}\text { NEW ENGLAND } \\
\text { Maine } \\
\text { N.H. } \\
\text { Vt. } \\
\text { Mass. } \\
\text { R.I. } \\
\text { Conn. }\end{array}$ & $\begin{array}{r}240 \\
8 \\
4 \\
3 \\
169 \\
19 \\
37\end{array}$ & $\begin{array}{r}446 \\
4 \\
11 \\
4 \\
368 \\
17 \\
42\end{array}$ & $\begin{array}{r}218 \\
12 \\
7 \\
- \\
137 \\
20 \\
42\end{array}$ & $\begin{array}{r}421 \\
- \\
11 \\
3 \\
348 \\
12 \\
47\end{array}$ & $\begin{array}{r}54 \\
1 \\
1 \\
- \\
36 \\
4 \\
12\end{array}$ & $\begin{array}{r}40 \\
- \\
1 \\
3 \\
22 \\
1 \\
13\end{array}$ & $\begin{array}{r}249 \\
9 \\
8 \\
2 \\
151 \\
24 \\
55\end{array}$ & $\begin{array}{r}273 \\
12 \\
6 \\
1 \\
152 \\
28 \\
74\end{array}$ \\
\hline $\begin{array}{l}\text { MID. ATLANTIC } \\
\text { Upstate N.Y. } \\
\text { N.Y. City } \\
\text { N.J. } \\
\text { Pa. }\end{array}$ & $\begin{array}{r}1,407 \\
525 \\
551 \\
210 \\
121\end{array}$ & $\begin{array}{r}646 \\
180 \\
218 \\
151 \\
97\end{array}$ & $\begin{array}{l}821 \\
166 \\
378 \\
135 \\
142\end{array}$ & $\begin{array}{r}462 \\
44 \\
152 \\
152 \\
114\end{array}$ & $\begin{array}{r}181 \\
8 \\
83 \\
34 \\
56\end{array}$ & $\begin{array}{r}196 \\
15 \\
84 \\
46 \\
51\end{array}$ & $\begin{array}{r}1,497 \\
165 \\
832 \\
352 \\
148\end{array}$ & $\begin{array}{r}1,689 \\
213 \\
873 \\
354 \\
249\end{array}$ \\
\hline $\begin{array}{l}\text { E.N. CENTRAL } \\
\text { Ohio } \\
\text { Ind. } \\
\text { Ill. } \\
\text { Mich. } \\
\text { Wis. }\end{array}$ & $\begin{array}{r}2,556 \\
230 \\
1,076 \\
601 \\
501 \\
148\end{array}$ & $\begin{array}{r}1,823 \\
310 \\
158 \\
734 \\
261 \\
360\end{array}$ & $\begin{array}{r}711 \\
96 \\
110 \\
2 \\
463 \\
40\end{array}$ & $\begin{array}{r}990 \\
90 \\
52 \\
577 \\
214 \\
57\end{array}$ & $\begin{array}{r}722 \\
53 \\
264 \\
190 \\
182 \\
33\end{array}$ & $\begin{array}{r}770 \\
62 \\
265 \\
287 \\
129 \\
27\end{array}$ & $\begin{array}{r}810 \\
197 \\
54 \\
387 \\
117 \\
55\end{array}$ & $\begin{array}{r}1,019 \\
160 \\
92 \\
497 \\
205 \\
65\end{array}$ \\
\hline $\begin{array}{l}\text { W.N. CENTRAL } \\
\text { Minn. } \\
\text { lowa } \\
\text { Mo. } \\
\text { N. Dak. } \\
\text { S. Dak. } \\
\text { Nebr. } \\
\text { Kans. }\end{array}$ & $\begin{array}{r}1,395 \\
359 \\
367 \\
456 \\
10 \\
4 \\
67 \\
132\end{array}$ & $\begin{array}{r}803 \\
157 \\
19 \\
526 \\
2 \\
10 \\
51 \\
38\end{array}$ & $\begin{array}{r}1,091 \\
438 \\
217 \\
340 \\
11 \\
3 \\
9 \\
73\end{array}$ & $\begin{array}{r}556 \\
184 \\
20 \\
274 \\
2 \\
6 \\
39 \\
31\end{array}$ & $\begin{array}{r}41 \\
4 \\
10 \\
22 \\
- \\
- \\
2 \\
3\end{array}$ & $\begin{array}{r}96 \\
9 \\
8 \\
63 \\
- \\
- \\
6 \\
10\end{array}$ & $\begin{array}{r}291 \\
97 \\
25 \\
114 \\
2 \\
13 \\
11 \\
29\end{array}$ & $\begin{array}{r}316 \\
124 \\
29 \\
116 \\
2 \\
9 \\
9 \\
12 \\
24\end{array}$ \\
\hline $\begin{array}{l}\text { S. ATLANTIC } \\
\text { Del. } \\
\text { Md. } \\
\text { D.C. } \\
\text { Va. } \\
\text { W. Va. } \\
\text { N.C. } \\
\text { S.C. } \\
\text { Ga. } \\
\text { Fla. }\end{array}$ & $\begin{array}{r}1,837 \\
11 \\
136 \\
38 \\
308 \\
3 \\
104 \\
86 \\
157 \\
994\end{array}$ & $\begin{array}{r}1,538 \\
10 \\
100 \\
38 \\
75 \\
7 \\
144 \\
87 \\
137 \\
940\end{array}$ & $\begin{array}{r}537 \\
10 \\
62 \\
U \\
221 \\
3 \\
61 \\
64 \\
54 \\
62\end{array}$ & $\begin{array}{r}376 \\
5 \\
31 \\
U \\
44 \\
3 \\
65 \\
46 \\
58 \\
124\end{array}$ & $\begin{array}{r}1,277 \\
7 \\
187 \\
35 \\
85 \\
2 \\
346 \\
131 \\
239 \\
245\end{array}$ & $\begin{array}{r}1,456 \\
6 \\
262 \\
34 \\
113 \\
3 \\
341 \\
184 \\
286 \\
227\end{array}$ & $\begin{array}{r}1,578 \\
- \\
167 \\
16 \\
152 \\
21 \\
208 \\
76 \\
346 \\
592\end{array}$ & $\begin{array}{r}2,048 \\
21 \\
173 \\
36 \\
186 \\
32 \\
302 \\
194 \\
400 \\
704\end{array}$ \\
\hline $\begin{array}{l}\text { E.S. CENTRAL } \\
\text { Ky. } \\
\text { Tenn. } \\
\text { Ala. } \\
\text { Miss. }\end{array}$ & $\begin{array}{r}605 \\
204 \\
246 \\
37 \\
118\end{array}$ & $\begin{array}{r}867 \\
178 \\
538 \\
78 \\
73\end{array}$ & $\begin{array}{r}340 \\
51 \\
260 \\
26 \\
3\end{array}$ & $\begin{array}{r}535 \\
122 \\
363 \\
44 \\
6\end{array}$ & $\begin{array}{r}574 \\
58 \\
346 \\
81 \\
89\end{array}$ & $\begin{array}{r}761 \\
70 \\
426 \\
151 \\
114\end{array}$ & $\begin{array}{r}479 \\
68 \\
216 \\
195 \\
-\end{array}$ & $\begin{array}{l}660 \\
109 \\
227 \\
202 \\
122\end{array}$ \\
\hline $\begin{array}{l}\text { W.S. CENTRAL } \\
\text { Ark. } \\
\text { La. } \\
\text { Okla. } \\
\text { Tex. }\end{array}$ & $\begin{array}{r}1,273 \\
146 \\
80 \\
79 \\
968\end{array}$ & $\begin{array}{r}1,620 \\
58 \\
134 \\
400 \\
1,028\end{array}$ & $\begin{array}{r}1,742 \\
44 \\
117 \\
26 \\
1,555\end{array}$ & $\begin{array}{r}694 \\
20 \\
68 \\
128 \\
478\end{array}$ & $\begin{array}{r}540 \\
68 \\
146 \\
87 \\
239\end{array}$ & $\begin{array}{r}689 \\
39 \\
200 \\
136 \\
314\end{array}$ & $\begin{array}{r}767 \\
130 \\
73 \\
85 \\
479\end{array}$ & $\begin{array}{r}1,422 \\
110 \\
99 \\
105 \\
1,108\end{array}$ \\
\hline $\begin{array}{l}\text { MOUNTAIN } \\
\text { Mont. } \\
\text { Idaho } \\
\text { Wyo. } \\
\text { Colo. } \\
\text { N. Mex. } \\
\text { Ariz. } \\
\text { Utah } \\
\text { Nev. }\end{array}$ & $\begin{array}{r}697 \\
6 \\
41 \\
2 \\
2 \\
123 \\
85 \\
293 \\
51 \\
96\end{array}$ & $\begin{array}{r}557 \\
7 \\
16 \\
3 \\
3 \\
101 \\
78 \\
270 \\
38 \\
44\end{array}$ & $\begin{array}{r}356 \\
- \\
- \\
2 \\
66 \\
53 \\
184 \\
51 \\
-\end{array}$ & $\begin{array}{r}380 \\
- \\
7 \\
1 \\
77 \\
55 \\
193 \\
41 \\
6\end{array}$ & $\begin{array}{r}150 \\
- \\
1 \\
1 \\
4 \\
19 \\
119 \\
1 \\
5\end{array}$ & $\begin{array}{r}147 \\
- \\
1 \\
- \\
1 \\
6 \\
133 \\
2 \\
4\end{array}$ & $\begin{array}{r}300 \\
10 \\
5 \\
2 \\
41 \\
29 \\
137 \\
31 \\
45\end{array}$ & $\begin{array}{r}348 \\
10 \\
12 \\
2 \\
47 \\
41 \\
148 \\
26 \\
62\end{array}$ \\
\hline $\begin{array}{l}\text { PACIFIC } \\
\text { Wash. } \\
\text { Oreg. } \\
\text { Calif. } \\
\text { Alaska } \\
\text { Hawaii }\end{array}$ & $\begin{array}{r}1,944 \\
338 \\
114 \\
1,457 \\
8 \\
27\end{array}$ & $\begin{array}{r}1,392 \\
68 \\
53 \\
1,246 \\
- \\
25\end{array}$ & $\begin{array}{r}391 \\
300 \\
68 \\
- \\
3 \\
20\end{array}$ & $\begin{array}{r}1,385 \\
68 \\
52 \\
1,241 \\
- \\
24\end{array}$ & $\begin{array}{r}266 \\
47 \\
5 \\
213 \\
- \\
1\end{array}$ & $\begin{array}{r}230 \\
48 \\
4 \\
175 \\
1 \\
2\end{array}$ & $\begin{array}{r}1,489 \\
166 \\
23 \\
1,151 \\
60 \\
89\end{array}$ & $\begin{array}{r}2,410 \\
160 \\
68 \\
2,029 \\
39 \\
114\end{array}$ \\
\hline $\begin{array}{l}\text { Guam } \\
\text { P.R. } \\
\text { V.I. } \\
\text { Amer. Samoa } \\
\text { C.N.M.I. }\end{array}$ & $\begin{array}{l}- \\
8 \\
- \\
- \\
-\end{array}$ & $\begin{array}{r}11 \\
102 \\
\cup \\
\cup \\
U\end{array}$ & $\begin{array}{l}U \\
U \\
U \\
U\end{array}$ & $\bigcup_{U}^{U}$ & $\begin{array}{r}- \\
85 \\
- \\
- \\
-\end{array}$ & $\begin{array}{r}109 \\
\cup \\
\cup\end{array}$ & $\begin{array}{l}- \\
- \\
- \\
- \\
-\end{array}$ & $\begin{array}{r}47 \\
151 \\
\cup \\
\cup\end{array}$ \\
\hline
\end{tabular}

$\mathrm{N}$ : Not notifiable. $\quad$ U: Unavailable. $\quad-:$ No reported cases.

* Individual cases can be reported through both the National Electronic Telecommunications System for Surveillance (NETSS) and the Public Health Laboratory Information System (PHLIS). 
TABLE III. Provisional cases of selected notifiable diseases preventable by vaccination, United States, weeks ending August 26, 2000, and August 28, 1999 (34th Week)

\begin{tabular}{|c|c|c|c|c|c|c|c|c|c|c|c|c|}
\hline \multirow[b]{3}{*}{ Reporting Area } & \multirow{2}{*}{\multicolumn{2}{|c|}{$\begin{array}{l}\text { H. influenzae, } \\
\text { Invasive }\end{array}$}} & \multicolumn{4}{|c|}{ Hepatitis (Viral), By Type } & \multicolumn{6}{|c|}{ Measles (Rubeola) } \\
\hline & & & \multicolumn{2}{|c|}{ A } & \multicolumn{2}{|c|}{ B } & \multicolumn{2}{|c|}{ Indigenous } & \multicolumn{2}{|c|}{ Imported* } & \multicolumn{2}{|c|}{ Total } \\
\hline & $\begin{array}{l}\text { Cum. } \\
2000^{+}\end{array}$ & $\begin{array}{l}\text { Cum. } \\
1999\end{array}$ & $\begin{array}{l}\text { Cum. } \\
2000 \\
\end{array}$ & $\begin{array}{l}\text { Cum. } \\
1999 \\
\end{array}$ & $\begin{array}{l}\text { Cum. } \\
2000 \\
\end{array}$ & $\begin{array}{l}\text { Cum. } \\
1999 \\
\end{array}$ & 2000 & $\begin{array}{l}\text { Cum. } \\
2000\end{array}$ & 2000 & $\begin{array}{l}\text { Cum. } \\
2000\end{array}$ & $\begin{array}{l}\text { Cum. } \\
2000 \\
\end{array}$ & $\begin{array}{l}\text { Cum. } \\
1999 \\
\end{array}$ \\
\hline UNITED STATES & 775 & 810 & 7,298 & 10,626 & 4,344 & 4,569 & 2 & 45 & - & 17 & 62 & 66 \\
\hline $\begin{array}{l}\text { NEW ENGLAND } \\
\text { Maine } \\
\text { N.H. } \\
\text { Vt. } \\
\text { Mass. } \\
\text { R.I. } \\
\text { Conn. }\end{array}$ & $\begin{array}{r}53 \\
1 \\
11 \\
4 \\
24 \\
1 \\
12\end{array}$ & $\begin{array}{r}59 \\
5 \\
11 \\
5 \\
23 \\
1 \\
14\end{array}$ & $\begin{array}{r}202 \\
14 \\
18 \\
9 \\
77 \\
15 \\
69\end{array}$ & $\begin{array}{r}181 \\
5 \\
10 \\
6 \\
71 \\
13 \\
76\end{array}$ & $\begin{array}{r}43 \\
5 \\
11 \\
6 \\
7 \\
14 \\
-\end{array}$ & $\begin{array}{r}101 \\
1 \\
10 \\
2 \\
35 \\
22 \\
31\end{array}$ & $\begin{array}{l}- \\
- \\
- \\
- \\
- \\
-\end{array}$ & $\begin{array}{l}2 \\
- \\
2 \\
- \\
- \\
- \\
-\end{array}$ & $\begin{array}{l}- \\
- \\
- \\
- \\
- \\
-\end{array}$ & $\begin{array}{l}4 \\
- \\
1 \\
3 \\
- \\
- \\
-\end{array}$ & $\begin{array}{l}6 \\
- \\
3 \\
3 \\
- \\
- \\
-\end{array}$ & $\begin{array}{r}10 \\
\overline{1} \\
- \\
7 \\
\overline{2}\end{array}$ \\
\hline $\begin{array}{l}\text { MID. ATLANTIC } \\
\text { Upstate N.Y. } \\
\text { N.Y. City } \\
\text { N.J. } \\
\text { Pa. }\end{array}$ & $\begin{array}{r}129 \\
67 \\
27 \\
26 \\
9\end{array}$ & $\begin{array}{r}142 \\
58 \\
42 \\
37 \\
5\end{array}$ & $\begin{array}{l}719 \\
139 \\
220 \\
119 \\
241\end{array}$ & $\begin{array}{l}766 \\
168 \\
226 \\
95 \\
277\end{array}$ & $\begin{array}{r}614 \\
93 \\
275 \\
83 \\
163\end{array}$ & $\begin{array}{r}573 \\
131 \\
174 \\
83 \\
185\end{array}$ & $\begin{array}{l}- \\
- \\
- \\
-\end{array}$ & $\begin{array}{r}13 \\
8 \\
5 \\
- \\
-\end{array}$ & $\begin{array}{l}- \\
- \\
- \\
-\end{array}$ & $\begin{array}{l}5 \\
- \\
4 \\
- \\
1\end{array}$ & $\begin{array}{r}18 \\
8 \\
9 \\
- \\
1\end{array}$ & $\begin{array}{l}5 \\
2 \\
3 \\
- \\
-\end{array}$ \\
\hline $\begin{array}{l}\text { E.N. CENTRAL } \\
\text { Ohio } \\
\text { Ind. } \\
\text { III. } \\
\text { Mich. } \\
\text { Wis. }\end{array}$ & $\begin{array}{r}110 \\
41 \\
22 \\
40 \\
7 \\
-\end{array}$ & $\begin{array}{r}139 \\
47 \\
20 \\
59 \\
10 \\
3\end{array}$ & $\begin{array}{r}891 \\
187 \\
51 \\
326 \\
314 \\
13\end{array}$ & $\begin{array}{r}2,018 \\
448 \\
72 \\
476 \\
970 \\
52\end{array}$ & $\begin{array}{r}472 \\
77 \\
33 \\
81 \\
280 \\
1\end{array}$ & $\begin{array}{r}477 \\
66 \\
31 \\
42 \\
312 \\
26\end{array}$ & $\begin{array}{l}- \\
- \\
- \\
- \\
-\end{array}$ & $\begin{array}{l}7 \\
2 \\
- \\
4 \\
1 \\
-\end{array}$ & $\begin{array}{l}- \\
- \\
- \\
- \\
-\end{array}$ & $\begin{array}{l}- \\
- \\
- \\
- \\
- \\
-\end{array}$ & $\begin{array}{l}7 \\
2 \\
- \\
4 \\
1 \\
-\end{array}$ & $\begin{array}{l}2 \\
- \\
1 \\
- \\
1 \\
-\end{array}$ \\
\hline $\begin{array}{l}\text { W.N. CENTRAL } \\
\text { Minn. } \\
\text { lowa } \\
\text { Mo. } \\
\text { N.Dak. } \\
\text { S. Dak. } \\
\text { Nebr. } \\
\text { Kans. }\end{array}$ & $\begin{array}{r}41 \\
22 \\
11 \\
1 \\
1 \\
4 \\
4 \\
3\end{array}$ & $\begin{array}{r}42 \\
24 \\
1 \\
5 \\
- \\
2 \\
4 \\
6\end{array}$ & $\begin{array}{r}629 \\
158 \\
58 \\
317 \\
2 \\
- \\
21 \\
73\end{array}$ & $\begin{array}{r}498 \\
45 \\
92 \\
303 \\
1 \\
8 \\
37 \\
12\end{array}$ & $\begin{array}{r}544 \\
25 \\
28 \\
448 \\
2 \\
- \\
23 \\
18\end{array}$ & $\begin{array}{r}182 \\
30 \\
28 \\
105 \\
- \\
1 \\
14 \\
4\end{array}$ & $\begin{array}{l}- \\
- \\
- \\
- \\
- \\
- \\
\end{array}$ & $\begin{array}{l}2 \\
- \\
2 \\
- \\
- \\
- \\
- \\
-\end{array}$ & $\begin{array}{l}- \\
- \\
- \\
- \\
- \\
-\end{array}$ & $\begin{array}{l}1 \\
1 \\
- \\
- \\
- \\
- \\
- \\
-\end{array}$ & $\begin{array}{l}3 \\
1 \\
2 \\
- \\
- \\
- \\
- \\
-\end{array}$ & $\begin{array}{l}- \\
- \\
- \\
- \\
- \\
-\end{array}$ \\
\hline $\begin{array}{l}\text { S. ATLANTIC } \\
\text { Del. } \\
\text { Md. } \\
\text { D.C. } \\
\text { Va. } \\
\text { W. Va. } \\
\text { N.C. } \\
\text { S.C. } \\
\text { Ga. } \\
\text { Fla. }\end{array}$ & $\begin{array}{r}208 \\
5 \overline{-} \\
54 \\
-\overline{-} \\
61 \\
6 \\
19 \\
11 \\
53 \\
34\end{array}$ & $\begin{array}{r}183 \\
- \\
47 \\
4 \\
14 \\
6 \\
28 \\
5 \\
49 \\
30\end{array}$ & $\begin{array}{r}919 \\
- \\
130 \\
20 \\
102 \\
48 \\
108 \\
39 \\
158 \\
314\end{array}$ & $\begin{array}{r}1,201 \\
2 \\
214 \\
48 \\
103 \\
27 \\
102 \\
28 \\
318 \\
359\end{array}$ & $\begin{array}{r}804 \\
81 \\
81 \\
24 \\
101 \\
7 \\
160 \\
7 \\
129 \\
295\end{array}$ & $\begin{array}{r}723 \\
1 \\
104 \\
17 \\
63 \\
17 \\
147 \\
57 \\
99 \\
218\end{array}$ & $\begin{array}{l}1 \\
- \\
- \\
- \\
- \\
- \\
- \\
- \\
1\end{array}$ & $\begin{array}{l}3 \\
- \\
- \\
- \\
2 \\
- \\
- \\
- \\
- \\
1\end{array}$ & $\begin{array}{l}- \\
- \\
- \\
- \\
- \\
- \\
- \\
- \\
-\end{array}$ & $\begin{array}{l}- \\
\overline{-} \\
- \\
- \\
- \\
- \\
- \\
-\end{array}$ & $\begin{array}{l}3 \\
- \\
- \\
- \\
2 \\
- \\
- \\
- \\
- \\
1\end{array}$ & $\begin{array}{l}5 \\
- \\
- \\
5 \\
3 \\
- \\
- \\
- \\
\end{array}$ \\
\hline $\begin{array}{l}\text { E.S. CENTRAL } \\
\text { Ky. } \\
\text { Tenn. } \\
\text { Ala. } \\
\text { Miss. }\end{array}$ & $\begin{array}{r}35 \\
12 \\
16 \\
6 \\
1\end{array}$ & $\begin{array}{r}50 \\
6 \\
26 \\
15 \\
3\end{array}$ & $\begin{array}{r}290 \\
34 \\
103 \\
44 \\
109\end{array}$ & $\begin{array}{r}284 \\
53 \\
115 \\
38 \\
78\end{array}$ & $\begin{array}{r}310 \\
55 \\
149 \\
35 \\
71\end{array}$ & $\begin{array}{r}324 \\
31 \\
164 \\
59 \\
70\end{array}$ & $\begin{array}{l}- \\
- \\
- \\
- \\
-\end{array}$ & $\begin{array}{l}- \\
- \\
- \\
- \\
-\end{array}$ & $\begin{array}{l}- \\
- \\
- \\
- \\
-\end{array}$ & $\begin{array}{l}- \\
- \\
- \\
- \\
-\end{array}$ & $\begin{array}{l}- \\
- \\
- \\
-\end{array}$ & $\begin{array}{l}2 \\
2 \\
- \\
- \\
-\end{array}$ \\
\hline $\begin{array}{l}\text { W.S. CENTRAL } \\
\text { Ark. } \\
\text { La. } \\
\text { Okla. } \\
\text { Tex. }\end{array}$ & $\begin{array}{r}43 \\
1 \\
7 \\
33 \\
2\end{array}$ & $\begin{array}{r}50 \\
2 \\
11 \\
33 \\
4\end{array}$ & $\begin{array}{r}1,178 \\
103 \\
29 \\
190 \\
856\end{array}$ & $\begin{array}{r}2,084 \\
31 \\
156 \\
376 \\
1,521\end{array}$ & $\begin{array}{r}445 \\
69 \\
52 \\
104 \\
220\end{array}$ & $\begin{array}{r}822 \\
50 \\
132 \\
106 \\
534\end{array}$ & $\begin{array}{l}- \\
- \\
- \\
- \\
-\end{array}$ & $\begin{array}{l}- \\
- \\
- \\
-\end{array}$ & $\begin{array}{l}- \\
- \\
- \\
- \\
-\end{array}$ & $\begin{array}{l}- \\
- \\
- \\
- \\
-\end{array}$ & $\begin{array}{l}- \\
- \\
- \\
- \\
-\end{array}$ & $\begin{array}{l}7 \\
- \\
- \\
- \\
7\end{array}$ \\
\hline $\begin{array}{l}\text { MOUNTAIN } \\
\text { Mont. } \\
\text { Idaho } \\
\text { Wyo. } \\
\text { Colo. } \\
\text { N. Mex. } \\
\text { Ariz. } \\
\text { Utah } \\
\text { Nev. }\end{array}$ & $\begin{array}{r}76 \\
1 \\
1 \\
3 \\
1 \\
11 \\
16 \\
36 \\
7 \\
1\end{array}$ & $\begin{array}{r}66 \\
1 \\
1 \\
1 \\
11 \\
18 \\
18 \\
28 \\
4 \\
2\end{array}$ & $\begin{array}{r}615 \\
4 \\
19 \\
10 \\
136 \\
56 \\
309 \\
39 \\
42\end{array}$ & $\begin{array}{r}869 \\
16 \\
31 \\
5 \\
160 \\
33 \\
499 \\
34 \\
91\end{array}$ & $\begin{array}{r}336 \\
5 \\
6 \\
3 \\
58 \\
85 \\
133 \\
16 \\
30\end{array}$ & $\begin{array}{r}408 \\
16 \\
21 \\
9 \\
67 \\
132 \\
102 \\
24 \\
37\end{array}$ & $\begin{array}{l}- \\
- \\
- \\
- \\
- \\
- \\
- \\
- \\
-\end{array}$ & $\begin{array}{c}11 \\
- \\
- \\
- \\
1 \\
- \\
- \\
3 \\
7\end{array}$ & $\begin{array}{l}- \\
- \\
- \\
- \\
- \\
- \\
- \\
-\end{array}$ & $\begin{array}{l}1 \\
- \\
- \\
- \\
1 \\
- \\
- \\
- \\
-\end{array}$ & $\begin{array}{c}12 \\
- \\
- \\
- \\
2 \\
- \\
- \\
3 \\
7\end{array}$ & $\begin{array}{l}1 \\
- \\
- \\
- \\
- \\
- \\
1 \\
- \\
-\end{array}$ \\
\hline $\begin{array}{l}\text { PACIFIC } \\
\text { Wash. } \\
\text { Oreg. } \\
\text { Calif. } \\
\text { Alaska } \\
\text { Hawaii }\end{array}$ & $\begin{array}{r}80 \\
5 \\
20 \\
28 \\
6 \\
21\end{array}$ & $\begin{array}{r}79 \\
3 \\
28 \\
39 \\
5 \\
4\end{array}$ & $\begin{array}{r}1,855 \\
179 \\
135 \\
1,529 \\
9 \\
3\end{array}$ & $\begin{array}{r}2,725 \\
215 \\
174 \\
2,313 \\
6 \\
17\end{array}$ & $\begin{array}{r}776 \\
53 \\
66 \\
643 \\
8 \\
6\end{array}$ & $\begin{array}{r}959 \\
44 \\
72 \\
820 \\
13 \\
10\end{array}$ & $\begin{array}{l}1 \\
\\
1 \\
- \\
-\end{array}$ & $\begin{array}{l}7 \\
2 \\
- \\
4 \\
1 \\
-\end{array}$ & $\begin{array}{l}- \\
- \\
- \\
- \\
-\end{array}$ & $\begin{array}{l}6 \\
1 \\
- \\
3 \\
- \\
2\end{array}$ & $\begin{array}{r}13 \\
3 \\
- \\
7 \\
1 \\
2\end{array}$ & $\begin{array}{r}34 \\
5 \\
12 \\
16 \\
- \\
1\end{array}$ \\
\hline $\begin{array}{l}\text { Guam } \\
\text { P.R. } \\
\text { V.I. } \\
\text { Amer. Samoa } \\
\text { C.N.M.I. }\end{array}$ & $\begin{array}{l}- \\
1 \\
- \\
- \\
-\end{array}$ & $\begin{array}{l}- \\
2 \\
U \\
U\end{array}$ & $\begin{array}{r}- \\
83 \\
- \\
- \\
-\end{array}$ & $\begin{array}{r}1 \\
U \\
U\end{array}$ & $\begin{array}{r}90 \\
- \\
- \\
-\end{array}$ & $\begin{array}{r}2 \\
151 \\
U \\
U\end{array}$ & $\begin{array}{l}U \\
- \\
U \\
U\end{array}$ & $\begin{array}{l}- \\
- \\
- \\
- \\
-\end{array}$ & $\begin{array}{l}U \\
- \\
U \\
U\end{array}$ & $\begin{array}{l}- \\
- \\
- \\
- \\
-\end{array}$ & $\begin{array}{l}- \\
- \\
- \\
-\end{array}$ & $\begin{array}{l}1 \\
\bar{U} \\
U\end{array}$ \\
\hline
\end{tabular}


TABLE III. (Cont'd) Provisional cases of selected notifiable diseases preventable by vaccination, United States, weeks ending August 26, 2000, and August 28, 1999 (34th Week)

\begin{tabular}{|c|c|c|c|c|c|c|c|c|c|c|c|}
\hline \multirow[b]{2}{*}{ Reporting Area } & \multicolumn{2}{|c|}{$\begin{array}{c}\text { Meningococcal } \\
\text { Disease }\end{array}$} & \multicolumn{3}{|c|}{ Mumps } & \multicolumn{3}{|c|}{ Pertussis } & \multicolumn{3}{|c|}{ Rubella } \\
\hline & $\begin{array}{l}\text { Cum. } \\
2000\end{array}$ & $\begin{array}{l}\text { Cum. } \\
1999\end{array}$ & 2000 & $\begin{array}{l}\text { Cum. } \\
2000\end{array}$ & $\begin{array}{l}\text { Cum. } \\
1999\end{array}$ & 2000 & $\begin{array}{l}\text { Cum. } \\
2000\end{array}$ & $\begin{array}{l}\text { Cum. } \\
1999\end{array}$ & 2000 & $\begin{array}{l}\text { Cum. } \\
2000\end{array}$ & $\begin{array}{l}\text { Cum. } \\
1999\end{array}$ \\
\hline UNITED STATES & 1,439 & 1,690 & 5 & 245 & 249 & 108 & 3,655 & 3,898 & - & 110 & 218 \\
\hline $\begin{array}{l}\text { NEW ENGLAND } \\
\text { Maine } \\
\text { N.H. } \\
\text { Vt. } \\
\text { Mass. } \\
\text { R.I. } \\
\text { Conn. }\end{array}$ & $\begin{array}{r}86 \\
8 \\
9 \\
2 \\
51 \\
7 \\
9\end{array}$ & $\begin{array}{r}77 \\
5 \\
11 \\
4 \\
41 \\
4 \\
12\end{array}$ & $\begin{array}{l}- \\
- \\
- \\
- \\
- \\
\bar{U}\end{array}$ & $\begin{array}{l}3 \\
- \\
- \\
- \\
- \\
1 \\
2\end{array}$ & $\begin{array}{l}6 \\
- \\
1 \\
1 \\
4 \\
- \\
-\end{array}$ & $\begin{array}{r}21 \\
16 \\
- \\
2 \\
1 \\
2 \\
\mathrm{U}\end{array}$ & $\begin{array}{r}871 \\
30 \\
79 \\
166 \\
547 \\
14 \\
35\end{array}$ & $\begin{array}{r}459 \\
- \\
72 \\
37 \\
318 \\
20 \\
12\end{array}$ & $\begin{array}{l}- \\
- \\
- \\
- \\
- \\
\bar{U}\end{array}$ & $\begin{array}{r}11 \\
- \\
2 \\
8 \\
- \\
1\end{array}$ & $\begin{array}{l}7 \\
- \\
- \\
7 \\
- \\
-\end{array}$ \\
\hline $\begin{array}{l}\text { MID. ATLANTIC } \\
\text { Upstate N.Y. } \\
\text { N.Y. City } \\
\text { N.J. } \\
\text { Pa. }\end{array}$ & $\begin{array}{r}139 \\
45 \\
30 \\
28 \\
36\end{array}$ & $\begin{array}{r}160 \\
44 \\
47 \\
36 \\
33\end{array}$ & $\begin{array}{l}1 \\
1 \\
- \\
- \\
-\end{array}$ & $\begin{array}{r}18 \\
7 \\
4 \\
3 \\
4\end{array}$ & $\begin{array}{r}33 \\
6 \\
9 \\
1 \\
17\end{array}$ & $\begin{array}{r}13 \\
7 \\
- \\
6 \\
-\end{array}$ & $\begin{array}{r}353 \\
159 \\
42 \\
34 \\
118\end{array}$ & $\begin{array}{r}653 \\
529 \\
30 \\
17 \\
77\end{array}$ & $\begin{array}{l}- \\
- \\
- \\
- \\
-\end{array}$ & $\begin{array}{l}9 \\
2 \\
7 \\
- \\
-\end{array}$ & $\begin{array}{r}27 \\
17 \\
4 \\
3 \\
3\end{array}$ \\
\hline $\begin{array}{l}\text { E.N. CENTRAL } \\
\text { Ohio } \\
\text { Ind. } \\
\text { III. } \\
\text { Mich. } \\
\text { Wis. }\end{array}$ & $\begin{array}{r}246 \\
61 \\
35 \\
64 \\
66 \\
20\end{array}$ & $\begin{array}{r}298 \\
107 \\
41 \\
80 \\
44 \\
26\end{array}$ & $\begin{array}{l}- \\
- \\
- \\
\bar{U}\end{array}$ & $\begin{array}{r}25 \\
7 \\
- \\
6 \\
12 \\
-\end{array}$ & $\begin{array}{r}34 \\
11 \\
4 \\
9 \\
8 \\
2\end{array}$ & $\begin{array}{r}23 \\
19 \\
- \\
4 \\
- \\
\end{array}$ & $\begin{array}{r}417 \\
224 \\
52 \\
45 \\
47 \\
49\end{array}$ & $\begin{array}{r}358 \\
149 \\
46 \\
67 \\
32 \\
64\end{array}$ & $\begin{array}{l}- \\
- \\
- \\
- \\
\bar{U}\end{array}$ & $\begin{array}{l}1 \\
- \\
- \\
1 \\
- \\
-\end{array}$ & $\begin{array}{l}2 \\
- \\
1 \\
1 \\
- \\
-\end{array}$ \\
\hline $\begin{array}{l}\text { W.N. CENTRAL } \\
\text { Minn. } \\
\text { lowa } \\
\text { Mo. } \\
\text { N. Dak. } \\
\text { S. Dak. } \\
\text { Nebr. } \\
\text { Kans. }\end{array}$ & $\begin{array}{r}120 \\
14 \\
21 \\
69 \\
2 \\
5 \\
4 \\
5\end{array}$ & $\begin{array}{r}164 \\
36 \\
29 \\
60 \\
3 \\
10 \\
9 \\
17\end{array}$ & $\begin{array}{l}- \\
- \\
- \\
- \\
- \\
- \\
\end{array}$ & $\begin{array}{r}16 \\
- \\
6 \\
5 \\
- \\
- \\
3 \\
2\end{array}$ & $\begin{array}{l}9 \\
1 \\
4 \\
1 \\
- \\
- \\
- \\
3\end{array}$ & $\begin{array}{c}17 \\
17 \\
- \\
- \\
- \\
- \\
\bar{U}\end{array}$ & $\begin{array}{r}262 \\
161 \\
32 \\
36 \\
2 \\
3 \\
5 \\
23\end{array}$ & $\begin{array}{r}216 \\
79 \\
33 \\
46 \\
4 \\
5 \\
3 \\
46\end{array}$ & $\begin{array}{l}- \\
- \\
- \\
- \\
- \\
- \\
\end{array}$ & $\begin{array}{l}- \\
- \\
- \\
- \\
- \\
- \\
-\end{array}$ & $\begin{array}{r}123 \\
5 \\
29 \\
2 \\
- \\
- \\
87 \\
-\end{array}$ \\
\hline $\begin{array}{l}\text { S. ATLANTIC } \\
\text { Del. } \\
\text { Md. } \\
\text { D.C. } \\
\text { Va. } \\
\text { W. Va. } \\
\text { N.C. } \\
\text { S.C. } \\
\text { Ga. } \\
\text { Fla. }\end{array}$ & $\begin{array}{r}237 \\
- \\
22 \\
- \\
35 \\
10 \\
31 \\
17 \\
38 \\
84\end{array}$ & $\begin{array}{r}279 \\
7 \\
43 \\
3 \\
35 \\
4 \\
32 \\
33 \\
49 \\
73\end{array}$ & $\begin{array}{l}3 \\
- \\
- \\
- \\
2 \\
- \\
- \\
- \\
- \\
1\end{array}$ & $\begin{array}{r}40 \\
- \\
9 \\
- \\
8 \\
- \\
5 \\
11 \\
2 \\
5\end{array}$ & $\begin{array}{r}37 \\
- \\
3 \\
2 \\
8 \\
- \\
8 \\
3 \\
3 \\
10\end{array}$ & $\begin{array}{l}7 \\
- \\
1 \\
- \\
3 \\
- \\
- \\
2 \\
- \\
1\end{array}$ & $\begin{array}{r}300 \\
8 \\
74 \\
3 \\
44 \\
1 \\
69 \\
23 \\
25 \\
53\end{array}$ & $\begin{array}{r}270 \\
4 \\
84 \\
- \\
17 \\
2 \\
66 \\
14 \\
25 \\
58\end{array}$ & $\begin{array}{l}- \\
- \\
- \\
- \\
- \\
- \\
- \\
-\end{array}$ & $\begin{array}{r}61 \\
- \\
- \\
- \\
- \\
- \\
52 \\
7 \\
- \\
2\end{array}$ & $\begin{array}{r}31 \\
- \\
1 \\
- \\
- \\
30 \\
- \\
- \\
-\end{array}$ \\
\hline $\begin{array}{l}\text { E.S. CENTRAL } \\
\text { Ky. } \\
\text { Tenn. } \\
\text { Ala. } \\
\text { Miss. }\end{array}$ & $\begin{array}{r}103 \\
22 \\
43 \\
28 \\
10\end{array}$ & $\begin{array}{r}120 \\
23 \\
48 \\
30 \\
19\end{array}$ & $\begin{array}{l}- \\
- \\
- \\
-\end{array}$ & $\begin{array}{l}6 \\
- \\
2 \\
2 \\
2\end{array}$ & $\begin{array}{r}10 \\
- \\
- \\
7 \\
3\end{array}$ & $\begin{array}{l}5 \\
2 \\
- \\
3 \\
-\end{array}$ & $\begin{array}{r}75 \\
32 \\
25 \\
17 \\
1\end{array}$ & $\begin{array}{r}69 \\
20 \\
29 \\
17 \\
3\end{array}$ & $\begin{array}{l}- \\
- \\
- \\
-\end{array}$ & $\begin{array}{l}5 \\
1 \\
1 \\
3 \\
-\end{array}$ & $\begin{array}{l}2 \\
- \\
- \\
2 \\
-\end{array}$ \\
\hline $\begin{array}{l}\text { W.S. CENTRAL } \\
\text { Ark. } \\
\text { La. } \\
\text { Okla. } \\
\text { Tex. }\end{array}$ & $\begin{array}{r}103 \\
12 \\
28 \\
22 \\
41\end{array}$ & $\begin{array}{r}181 \\
31 \\
53 \\
27 \\
70\end{array}$ & $\begin{array}{l}- \\
- \\
- \\
-\end{array}$ & $\begin{array}{r}23 \\
2 \\
3 \\
- \\
18\end{array}$ & $\begin{array}{r}32 \\
\overline{7} \\
1 \\
24\end{array}$ & $\begin{array}{l}7 \\
- \\
- \\
- \\
7\end{array}$ & $\begin{array}{r}185 \\
26 \\
3 \\
6 \\
150\end{array}$ & $\begin{array}{r}133 \\
16 \\
9 \\
13 \\
95\end{array}$ & $\begin{array}{l}- \\
- \\
- \\
-\end{array}$ & $\begin{array}{l}4 \\
- \\
- \\
4\end{array}$ & $\begin{array}{l}6 \\
- \\
- \\
- \\
6\end{array}$ \\
\hline $\begin{array}{l}\text { MOUNTAIN } \\
\text { Mont. } \\
\text { Idaho } \\
\text { Wyo. } \\
\text { Colo. } \\
\text { N. Mex. } \\
\text { Ariz. } \\
\text { Utah } \\
\text { Nev. }\end{array}$ & $\begin{array}{r}99 \\
4 \\
6 \\
- \\
28 \\
7 \\
44 \\
7 \\
3\end{array}$ & $\begin{array}{r}100 \\
2 \\
8 \\
3 \\
27 \\
13 \\
29 \\
12 \\
6\end{array}$ & $\begin{array}{l}- \\
- \\
- \\
- \\
- \\
- \\
-\end{array}$ & $\begin{array}{r}15 \\
1 \\
- \\
1 \\
1 \\
1 \\
3 \\
4 \\
4\end{array}$ & $\begin{array}{r}10 \\
- \\
1 \\
- \\
3 \\
N \\
- \\
3 \\
3\end{array}$ & $\begin{array}{l}9 \\
- \\
- \\
- \\
5 \\
1 \\
3 \\
- \\
-\end{array}$ & $\begin{array}{r}492 \\
24 \\
47 \\
3 \\
268 \\
74 \\
52 \\
15 \\
9\end{array}$ & $\begin{array}{r}475 \\
2 \\
115 \\
2 \\
178 \\
64 \\
61 \\
49 \\
4\end{array}$ & $\begin{array}{l}- \\
- \\
- \\
- \\
- \\
- \\
-\end{array}$ & $\begin{array}{l}2 \\
- \\
- \\
- \\
1 \\
- \\
1 \\
- \\
-\end{array}$ & $\begin{array}{r}16 \\
- \\
- \\
- \\
1 \\
- \\
13 \\
1 \\
1\end{array}$ \\
\hline $\begin{array}{l}\text { PACIFIC } \\
\text { Wash. } \\
\text { Oreg. } \\
\text { Calif. } \\
\text { Alaska } \\
\text { Hawaii }\end{array}$ & $\begin{array}{r}306 \\
37 \\
45 \\
211 \\
5 \\
8\end{array}$ & $\begin{array}{r}311 \\
51 \\
55 \\
193 \\
6 \\
6\end{array}$ & $\begin{array}{r}1 \\
- \\
N \\
1 \\
- \\
-\end{array}$ & $\begin{array}{r}99 \\
5 \\
N \\
74 \\
7 \\
13\end{array}$ & $\begin{array}{r}78 \\
2 \\
N \\
63 \\
1 \\
12\end{array}$ & $\begin{array}{l}6 \\
6 \\
U \\
- \\
- \\
-\end{array}$ & $\begin{array}{r}700 \\
222 \\
85 \\
348 \\
19 \\
26\end{array}$ & $\begin{array}{r}1,265 \\
539 \\
26 \\
668 \\
4 \\
28\end{array}$ & $\begin{array}{l}- \\
- \\
\text { U } \\
- \\
-\end{array}$ & $\begin{array}{r}17 \\
7 \\
- \\
10 \\
- \\
-\end{array}$ & $\begin{array}{l}4 \\
- \\
- \\
4 \\
- \\
-\end{array}$ \\
\hline $\begin{array}{l}\text { Guam } \\
\text { P.R. } \\
\text { V.I. } \\
\text { Amer. Samoa } \\
\text { C.N.M.I. }\end{array}$ & $\begin{array}{l}- \\
5 \\
- \\
- \\
-\end{array}$ & $\begin{array}{l}1 \\
9 \\
\cup \\
\cup\end{array}$ & $\begin{array}{l}U \\
\bar{U} \\
U \\
U\end{array}$ & $\begin{array}{l}- \\
- \\
- \\
-\end{array}$ & $\begin{array}{l}1 \\
\bar{U} \\
\mathrm{U}\end{array}$ & $\begin{array}{l}U \\
\bar{U} \\
U \\
U\end{array}$ & $\begin{array}{l}- \\
2 \\
- \\
-\end{array}$ & $\begin{array}{c}1 \\
U_{U}^{1} \\
\cup\end{array}$ & $\begin{array}{l}U \\
- \\
U \\
U\end{array}$ & $\begin{array}{l}- \\
- \\
- \\
-\end{array}$ & $\begin{array}{c}- \\
\cup \\
\cup \\
\cup\end{array}$ \\
\hline
\end{tabular}

$\mathrm{N}$ : Not notifiable.

U: Unavailable.

- : No reported cases. 
TABLE IV. Deaths in 122 U.S. cities, ${ }^{*}$ week ending August 26, 2000 (34th Week)

\begin{tabular}{|c|c|c|c|c|c|c|c|c|c|c|c|c|c|c|c|}
\hline \multirow[b]{2}{*}{ Reporting Area } & \multicolumn{6}{|c|}{ All Causes, By Age (Years) } & \multirow{2}{*}{$\begin{array}{l}\text { P\&l } \\
\text { Total }\end{array}$} & \multirow[b]{2}{*}{ Reporting Area } & \multicolumn{6}{|c|}{ All Causes, By Age (Years) } & \multirow{2}{*}{$\begin{array}{c}\text { P\&I }^{\dagger} \\
\text { Total }\end{array}$} \\
\hline & $\begin{array}{c}\text { All } \\
\text { Ages }\end{array}$ & $\geq 65$ & $45-64$ & $25-44$ & $1-24$ & $<1$ & & & $\begin{array}{c}\text { All } \\
\text { Ages }\end{array}$ & $\geq 65$ & $45-64$ & $25-44$ & $1-24$ & $<1$ & \\
\hline $\begin{array}{l}\text { NEW ENGLAND } \\
\text { Boston, Mass. } \\
\text { Bridgeport, Conn. } \\
\text { Cambridge, Mass. } \\
\text { Fall River, Mass. } \\
\text { Hartford, Conn. } \\
\text { Lowell, Mass. } \\
\text { Lynn, Mass. } \\
\text { New Bedford, Mass. } \\
\text { New Haven, Conn. } \\
\text { Providence, R.I. } \\
\text { Somerville, Mass. } \\
\text { Springfield, Mass. } \\
\text { Waterbury, Conn. } \\
\text { Worcester, Mass. }\end{array}$ & $\begin{array}{r}478 \\
135 \\
35 \\
19 \\
22 \\
59 \\
24 \\
10 \\
25 \\
25 \\
39 \\
U \\
U \\
33 \\
20 \\
57\end{array}$ & $\begin{array}{r}331 \\
86 \\
29 \\
15 \\
18 \\
32 \\
16 \\
8 \\
19 \\
27 \\
U \\
U \\
25 \\
15 \\
41\end{array}$ & $\begin{array}{r}105 \\
30 \\
5 \\
3 \\
4 \\
22 \\
5 \\
2 \\
4 \\
7 \\
\cup \\
U \\
6 \\
2 \\
15\end{array}$ & $\begin{array}{r}27 \\
12 \\
1 \\
1 \\
- \\
3 \\
2 \\
- \\
2 \\
4 \\
U \\
U \\
- \\
2 \\
-\end{array}$ & $\begin{array}{l}3 \\
1 \\
- \\
- \\
- \\
1 \\
- \\
- \\
- \\
- \\
\\
U \\
1 \\
- \\
-\end{array}$ & $\begin{array}{r}12 \\
6 \\
- \\
- \\
- \\
1 \\
1 \\
- \\
- \\
1 \\
U \\
U \\
1 \\
1 \\
1\end{array}$ & $\begin{array}{r}44 \\
5 \\
3 \\
3 \\
- \\
7 \\
3 \\
- \\
3 \\
4 \\
\cup \\
U \\
4 \\
4 \\
8\end{array}$ & $\begin{array}{l}\text { S. ATLANTIC } \\
\text { Atlanta, Ga. } \\
\text { Baltimore, Md. } \\
\text { Charlotte, N.C. } \\
\text { Jacksonville, Fla. } \\
\text { Miami, Fla. } \\
\text { Norfolk, Va. } \\
\text { Richmond, Va. } \\
\text { Savannah, Ga. } \\
\text { St. Petersburg, Fla. } \\
\text { Tampa, Fla. } \\
\text { Washington, D.C. } \\
\text { Wilmington, Del. } \\
\text { E.S. CENTRAL } \\
\text { Rirmingham }\end{array}$ & $\begin{array}{r}1,091 \\
\mathrm{U} \\
191 \\
103 \\
154 \\
104 \\
65 \\
58 \\
53 \\
65 \\
65 \\
175 \\
100 \\
23 \\
921 \\
184\end{array}$ & $\begin{array}{r}683 \\
U \\
114 \\
68 \\
110 \\
50 \\
43 \\
30 \\
35 \\
45 \\
121 \\
61 \\
6 \\
601 \\
117\end{array}$ & $\begin{array}{r}220 \\
U \\
45 \\
18 \\
26 \\
21 \\
9 \\
16 \\
11 \\
12 \\
37 \\
21 \\
4\end{array}$ & $\begin{array}{r}115 \\
U \\
24 \\
8 \\
10 \\
15 \\
7 \\
3 \\
5 \\
5 \\
11 \\
14 \\
13\end{array}$ & $\begin{array}{r}43 \\
U \\
4 \\
3 \\
5 \\
16 \\
1 \\
3 \\
- \\
3 \\
5 \\
3 \\
-\end{array}$ & $\begin{array}{l}30 \\
U \\
4 \\
6 \\
3 \\
2 \\
5 \\
6 \\
2 \\
- \\
1 \\
1 \\
-\end{array}$ & $\begin{array}{r}67 \\
U \\
15 \\
9 \\
13 \\
- \\
1 \\
7 \\
4 \\
3 \\
10 \\
5 \\
- \\
73 \\
1\end{array}$ \\
\hline $\begin{array}{l}\text { MID. ATLANTIC } \\
\text { Albany, N.Y. } \\
\text { Allentown, Pa. } \\
\text { Buffalo, N.Y. } \\
\text { Camden, N.J. } \\
\text { Elizabeth, N.J. } \\
\text { Erie, Pa.§ } \\
\text { Jersey City, N.J. } \\
\text { New York City, N.Y. } \\
\text { Newark, N.J. } \\
\text { Paterson, N.J. } \\
\text { Philadelphia,Pa. } \\
\text { Pittsburgh, Pa.§ } \\
\text { Reading,Pa. } \\
\text { Rochester, N.Y. } \\
\text { Schenectady, N.Y. } \\
\text { Scranton, Pa.§ } \\
\text { Syracuse, N.Y. } \\
\text { Trenton, N.J. } \\
\text { Utica, N.Y. } \\
\text { Yonkers, N.Y. }\end{array}$ & $\begin{array}{r}2,213 \\
41 \\
18 \\
81 \\
40 \\
27 \\
31 \\
38 \\
1,103 \\
43 \\
19 \\
399 \\
67 \\
20 \\
130 \\
23 \\
36 \\
46 \\
27 \\
24 \\
U\end{array}$ & $\begin{array}{r}1,527 \\
31 \\
17 \\
64 \\
26 \\
9 \\
21 \\
28 \\
749 \\
19 \\
13 \\
262 \\
46 \\
18 \\
100 \\
19 \\
32 \\
35 \\
22 \\
16 \\
U\end{array}$ & $\begin{array}{r}427 \\
5 \\
1 \\
12 \\
5 \\
5 \\
6 \\
5 \\
5 \\
230 \\
10 \\
4 \\
92 \\
11 \\
- \\
17 \\
4 \\
3 \\
10 \\
4 \\
3 \\
U\end{array}$ & $\begin{array}{r}178 \\
- \\
- \\
4 \\
4 \\
1 \\
1 \\
3 \\
102 \\
11 \\
2 \\
34 \\
5 \\
- \\
5 \\
- \\
1 \\
1 \\
1 \\
3 \\
U\end{array}$ & $\begin{array}{r}39 \\
4 \\
- \\
- \\
1 \\
- \\
2 \\
- \\
10 \\
2 \\
- \\
8 \\
3 \\
2 \\
5 \\
- \\
- \\
- \\
- \\
2 \\
U\end{array}$ & $\begin{array}{r}41 \\
1 \\
- \\
1 \\
4 \\
12 \\
1 \\
2 \\
11 \\
1 \\
- \\
3 \\
2 \\
- \\
3 \\
- \\
- \\
- \\
- \\
- \\
\text { U }\end{array}$ & $\begin{array}{r}102 \\
- \\
2 \\
7 \\
1 \\
- \\
2 \\
- \\
38 \\
2 \\
1 \\
25 \\
4 \\
2 \\
8 \\
- \\
2 \\
6 \\
2 \\
- \\
U\end{array}$ & $\begin{array}{l}\text { W.S. CENTRAL } \\
\text { Austin, Tex. } \\
\text { Baton Rouge, La. } \\
\text { Corpus Christi, Tex. } \\
\text { Dallas, Tex. } \\
\text { EI Paso, Tex. } \\
\text { Ft. Worth, Tex. } \\
\text { Houston, Tex. } \\
\text { Little Rock, Ark. } \\
\text { New Orleans, La. } \\
\text { San Antonio, Tex. } \\
\text { Shreveport, La. } \\
\text { Tulsa, Okla. }\end{array}$ & $\begin{array}{r}74 \\
711 \\
119 \\
89 \\
209 \\
96 \\
26 \\
132 \\
1,485 \\
75 \\
44 \\
53 \\
204 \\
79 \\
93 \\
386 \\
60 \\
76 \\
221 \\
60 \\
134\end{array}$ & $\begin{array}{r}55 \\
72 \\
58 \\
137 \\
62 \\
17 \\
83 \\
927 \\
39 \\
32 \\
35 \\
123 \\
60 \\
57 \\
222 \\
38 \\
32 \\
156 \\
38 \\
95\end{array}$ & $\begin{array}{r}289 \\
15 \\
8 \\
10 \\
38 \\
13 \\
26 \\
87 \\
16 \\
7 \\
35 \\
13 \\
21\end{array}$ & $\begin{array}{r}156 \\
15 \\
2 \\
8 \\
26 \\
5 \\
5 \\
42 \\
3 \\
16 \\
18 \\
3 \\
13\end{array}$ & $\begin{array}{r}4 \\
1 \\
2 \\
1 \\
5 \\
3 \\
- \\
9 \\
77 \\
2 \\
2 \\
- \\
11 \\
- \\
- \\
23 \\
2 \\
21 \\
9 \\
4 \\
3\end{array}$ & $\begin{array}{r}36 \\
4 \\
- \\
- \\
6 \\
1 \\
5 \\
12 \\
1 \\
- \\
3 \\
2 \\
2\end{array}$ & $\begin{array}{r}21 \\
4 \\
2 \\
8 \\
18 \\
5 \\
7 \\
8 \\
79 \\
3 \\
1 \\
2 \\
7 \\
5 \\
6 \\
22 \\
4 \\
7 \\
16 \\
3 \\
3\end{array}$ \\
\hline $\begin{array}{l}\text { E.N. CENTRAL } \\
\text { Akron, Ohio } \\
\text { Canton, Ohio } \\
\text { Chicago, Ill. } \\
\text { Cincinnati, Ohio } \\
\text { Cleveland, Ohio } \\
\text { Columbus, Ohio } \\
\text { Dayton, Ohio } \\
\text { Detroit, Mich. } \\
\text { Evansville, Ind. } \\
\text { Fort Wayne, Ind. }\end{array}$ & $\begin{array}{r}2,059 \\
50 \\
33 \\
465 \\
112 \\
139 \\
203 \\
120 \\
179 \\
52 \\
38\end{array}$ & $\begin{array}{r}1,435 \\
39 \\
28 \\
303 \\
80 \\
93 \\
139 \\
92 \\
113 \\
39 \\
26\end{array}$ & $\begin{array}{r}395 \\
5 \\
4 \\
83 \\
18 \\
30 \\
42 \\
18 \\
47 \\
11 \\
9\end{array}$ & $\begin{array}{r}118 \\
3 \\
- \\
44 \\
6 \\
8 \\
13 \\
7 \\
12 \\
2 \\
2\end{array}$ & $\begin{array}{r}54 \\
1 \\
1 \\
15 \\
7 \\
1 \\
5 \\
1 \\
3 \\
- \\
1\end{array}$ & $\begin{array}{r}53 \\
2 \\
- \\
16 \\
1 \\
7 \\
4 \\
2 \\
4 \\
- \\
-\end{array}$ & $\begin{array}{r}120 \\
3 \\
2 \\
37 \\
8 \\
4 \\
8 \\
7 \\
11 \\
2 \\
3\end{array}$ & $\begin{array}{l}\text { MOUNTAIN } \\
\text { Albuquerque, N.M. } \\
\text { Boise, Idaho } \\
\text { Colo.Springs, Colo. } \\
\text { Denver, Colo. } \\
\text { Las Vegas, Nev. } \\
\text { Ogden, Utah } \\
\text { Phoenix, Ariz. } \\
\text { Pueblo, Colo. } \\
\text { Salt Lake City, Utah } \\
\text { Tucson, Ariz. }\end{array}$ & $\begin{array}{r}1,032 \\
108 \\
43 \\
\text {. } 56 \\
105 \\
223 \\
24 \\
161 \\
35 \\
137 \\
140\end{array}$ & $\begin{array}{r}645 \\
71 \\
34 \\
39 \\
57 \\
135 \\
14 \\
79 \\
27 \\
90 \\
99\end{array}$ & $\begin{array}{r}231 \\
26 \\
6 \\
8 \\
25 \\
57 \\
5 \\
40 \\
5 \\
29 \\
30\end{array}$ & $\begin{array}{r}99 \\
6 \\
1 \\
7 \\
12 \\
21 \\
2 \\
25 \\
2 \\
14 \\
9\end{array}$ & $\begin{array}{r}27 \\
3 \\
1 \\
1 \\
3 \\
6 \\
1 \\
8 \\
1 \\
1 \\
2\end{array}$ & $\begin{array}{r}30 \\
2 \\
1 \\
1 \\
8 \\
4 \\
2 \\
9 \\
- \\
3 \\
-\end{array}$ & $\begin{array}{r}52 \\
13 \\
1 \\
1 \\
6 \\
11 \\
2 \\
1 \\
2 \\
10 \\
5\end{array}$ \\
\hline $\begin{array}{l}\text { Gary, Ind. } \\
\text { Grand Rapids, Mich. } \\
\text { Indianapolis, Ind. } \\
\text { Lansing, Mich. } \\
\text { Milwaukee, Wis. } \\
\text { Peoria, III. } \\
\text { Rockford, III. } \\
\text { South Bend, Ind. } \\
\text { Toledo, Ohio } \\
\text { Youngstown, Ohio }\end{array}$ & $\begin{array}{r}27 \\
56 \\
187 \\
31 \\
97 \\
42 \\
48 \\
36 \\
91 \\
53\end{array}$ & $\begin{array}{r}14 \\
36 \\
129 \\
19 \\
71 \\
36 \\
35 \\
29 \\
71 \\
43\end{array}$ & $\begin{array}{r}8 \\
12 \\
34 \\
9 \\
19 \\
4 \\
12 \\
6 \\
15 \\
9\end{array}$ & $\begin{array}{l}2 \\
2 \\
8 \\
2 \\
1 \\
1 \\
- \\
1 \\
3 \\
1\end{array}$ & $\begin{array}{l}3 \\
4 \\
9 \\
- \\
2 \\
- \\
- \\
- \\
1 \\
-\end{array}$ & $\begin{array}{l}- \\
2 \\
7 \\
1 \\
4 \\
1 \\
1 \\
- \\
1 \\
-\end{array}$ & $\begin{array}{l}- \\
4 \\
4 \\
3 \\
9 \\
1 \\
4 \\
2 \\
5 \\
3\end{array}$ & $\begin{array}{l}\text { PACIFIC } \\
\text { Berkeley, Calif. } \\
\text { Fresno, Calif. } \\
\text { Glendale, Calif. } \\
\text { Honolulu, Hawaii } \\
\text { Long Beach, Calif. } \\
\text { Los Angeles, Calif. } \\
\text { Pasadena, Calif. } \\
\text { Portland, Oreg. } \\
\text { Sacramento, Calif. }\end{array}$ & $\begin{array}{r}1,621 \\
20 \\
99 \\
16 \\
96 \\
61 \\
323 \\
31 \\
169 \\
161\end{array}$ & $\begin{array}{r}1,133 \\
10 \\
76 \\
13 \\
74 \\
48 \\
202 \\
20 \\
115 \\
116\end{array}$ & $\begin{array}{r}279 \\
5 \\
12 \\
1 \\
11 \\
9 \\
64 \\
8 \\
31 \\
29\end{array}$ & $\begin{array}{r}123 \\
4 \\
8 \\
1 \\
6 \\
4 \\
35 \\
2 \\
16 \\
6\end{array}$ & $\begin{array}{r}47 \\
1 \\
1 \\
1 \\
2 \\
- \\
17 \\
- \\
4 \\
6\end{array}$ & $\begin{array}{r}36 \\
- \\
2 \\
- \\
3 \\
- \\
5 \\
1 \\
2 \\
3\end{array}$ & $\begin{array}{r}131 \\
1 \\
7 \\
1 \\
6 \\
7 \\
17 \\
3 \\
9 \\
18\end{array}$ \\
\hline $\begin{array}{l}\text { W.N. CENTRAL } \\
\text { Des Moines, Iowa } \\
\text { Duluth, Minn. } \\
\text { Kansas City, Kans. } \\
\text { Kansas City, Mo. } \\
\text { Lincoln, Nebr. } \\
\text { Minneapolis, Minn. } \\
\text { Omaha, Nebr. } \\
\text { St. Louis, Mo. } \\
\text { St. Paul, Minn. } \\
\text { Wichita, Kans. }\end{array}$ & $\begin{array}{r}802 \\
52 \\
30 \\
22 \\
99 \\
49 \\
192 \\
83 \\
100 \\
100 \\
75\end{array}$ & $\begin{array}{r}551 \\
36 \\
23 \\
11 \\
72 \\
35 \\
132 \\
56 \\
54 \\
77 \\
55\end{array}$ & $\begin{array}{r}168 \\
6 \\
6 \\
8 \\
18 \\
11 \\
40 \\
20 \\
29 \\
16 \\
14\end{array}$ & $\begin{array}{r}43 \\
6 \\
1 \\
1 \\
6 \\
3 \\
9 \\
3 \\
6 \\
5 \\
3\end{array}$ & $\begin{array}{r}27 \\
3 \\
- \\
2 \\
1 \\
- \\
9 \\
3 \\
6 \\
2 \\
1\end{array}$ & $\begin{array}{r}13 \\
1 \\
- \\
- \\
2 \\
- \\
2 \\
1 \\
5 \\
- \\
2\end{array}$ & $\begin{array}{r}52 \\
5 \\
2 \\
3 \\
5 \\
3 \\
17 \\
4 \\
- \\
9 \\
4\end{array}$ & $\begin{array}{l}\text { San Diego, Calif. } \\
\text { San Francisco, Calif. } \\
\text { San Jose, Calif. } \\
\text { Santa Cruz, Calif. } \\
\text { Seattle, Wash. } \\
\text { Spokane, Wash. } \\
\text { Tacoma, Wash. }\end{array}$ & 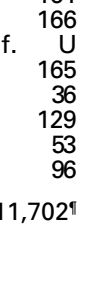 & $\begin{array}{r}114 \\
\mathrm{U} \\
115 \\
28 \\
91 \\
40 \\
71\end{array}$ & $\begin{array}{r}23 \\
U \\
35 \\
8 \\
19 \\
6 \\
18\end{array}$ & $\begin{array}{r}16 \\
U \\
6 \\
- \\
10 \\
4 \\
5\end{array}$ & $\begin{array}{l}6 \\
U \\
5 \\
- \\
2 \\
2 \\
-\end{array}$ & $\begin{array}{l}7 \\
U \\
4 \\
- \\
7 \\
1 \\
1\end{array}$ & $\begin{array}{r}20 \\
\cup \\
16 \\
3 \\
7 \\
7 \\
9\end{array}$ \\
\hline
\end{tabular}

U: Unavailable. -:No reported cases.

* Mortality data in this table are voluntarily reported from 122 cities in the United States, most of which have populations of $\geq 100,000$. A death is reported by the place of its occurrence and by the week that the death certificate was filed. Fetal deaths are not included.

†Pneumonia and influenza.

${ }^{\S}$ Because of changes in reporting methods in this Pennsylvania city, these numbers are partial counts for the current week. Complete counts will be available in 4 to 6 weeks.

iTotal includes unknown ages. 
Notices to Readers - Continued

3. Martinez R. Statement of the honorable Ricardo Martinez, M.D., Administrator, National Highway Traffic Safety Administration, before the Subcommittee on Surface Transportation, Committee on Transportation and Infrastructure, U.S. House of Representatives, July 17, 1997. Available at http://www.nhtsa.dot.gov/nhtsa/announce/testimony/aggres2.html. Accessed August 2000.

4. National Highway Traffic Safety Administration. Traffic safety facts, 1998: pedestrians. Washington, DC: National Highway Traffic Safety Administration, 1999 (DOT HS 808 958).

5. National Institute for Occupational Safety and Health. Preventing worker injuries and deaths from traffic-related motor vehicle crashes. Cincinnati, Ohio: US Department of Health and Human Services, 1998. DHHS (NIOSH) publication no. 98-142.

\section{Notice to Readers}

\section{Availability of Influenza Pandemic Preparedness Planning FluAid, 2.0}

Influenza pandemics have occurred three times during the 20th century: 1918, 1957, and 1968. Experts predict that another influenza pandemic is likely, if not inevitable. Prepandemic planning is essential if influenza pandemic-related morbidity, mortality, and social disruption are to be minimized. To help state and local public health officials and policy makers prepare for the next influenza pandemic, CDC has developed FluAid, 2.0, a specialized software that estimates the number of deaths, hospitalizations, and outpatient visits that may occur during the next pandemic. The software also will help planners calculate the potential burden of an influenza pandemic on health-care resources (e.g., number of hospital beds required and doctors available to see outpatients as a percentage of existing capacity).

Starting September 1, 2000, FluAid, 2.0 will be available from the National Vaccine Program Office's World-Wide Web site, http://www.cdc.gov/od/nvpo/pandemics/. The software can be downloaded or can be accessed as an online calculator. A manual is provided explaining the software, required data inputs, and suggestions for data sources. FluAid is in the public domain and available free of charge.

\section{Contributors to the Production of the MMWR (Weekly)}

Weekly Notifiable Disease Morbidity Data and 122 Cities Mortality Data

Samuel L. Groseclose, D.V.M., M.P.H.

State Support Team

Robert Fagan

Jose Aponte

Gerald Jones

David Nitschke

Scott Noldy

Carol A. Worsham
CDC Operations Team

Carol M. Knowles

Deborah A. Adams

Willie J. Anderson

Patsy A. Hall

Suzette A. Park

Felicia J. Perry

Pearl Sharp

Informatics

T. Demetri Vacalis, Ph.D. 
The Morbidity and Mortality Weekly Report (MMWR) Series is prepared by the Centers for Disease Control and Prevention (CDC) and is available free of charge in electronic format and on a paid subscription basis for paper copy. To receive an electronic copy on Friday of each week, send an e-mail message to listserv@listserv.cdc.gov. The body content should read SUBscribe mmwr-toc. Electronic copy also is available from CDC's World-Wide Web server at http://www.cdc.gov/ or from CDC's file transfer protocol server at ftp.cdc.gov. To subscribe for paper copy, contact Superintendent of Documents, U.S. Government Printing Office, Washington, DC 20402; telephone (202) 512-1800.

Data in the weekly MMWR are provisional, based on weekly reports to CDC by state health departments. The reporting week concludes at close of business on Friday; compiled data on a national basis are officially released to the public on the following Friday. Address inquiries about the MMWR Series, including material to be considered for publication, to: Editor, MMWR Series, Mailstop C-08, CDC, 1600 Clifton Rd., N.E., Atlanta, GA 30333; telephone (888) 232-3228.

All material in the MMWR Series is in the public domain and may be used and reprinted without permission; citation as to source, however, is appreciated.
Director, Centers for Disease
Acting Director,
Control and Prevention
Epidemiology Program Office
Barbara R. Holloway, M.P.H.
Writers-Editors, MMWR (Weekly)
Jeffrey P. Koplan, M.D., M.P.H.
Jill Crane
David C. Johnson
Editor, MMWR Series
John W. Ward, M.D.
Public Health, Centers for Disease
Control and Prevention
David W. Fleming, M.D.
Acting Managing Editor, MMWR
(Weekly)
Teresa F. Rutledge
Desktop Publishing
Michael T. Brown
Lynda G. Cupell
Morie M. Higgins

ఓU.S. Government Printing Office: 2000-533-206/28036 Region IV 